\title{
Multiresidue Analysis of Pesticides in Three Indian Soils: Method Development and Validation Using Gas Chromatography Tandem Mass Spectrometry
}

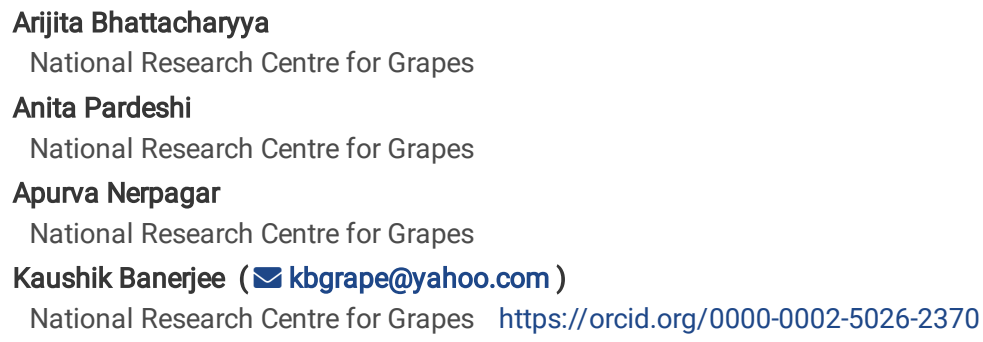




\section{Abstract}

The paper aimed to develop an effective multiresidue extraction method in three major soil types, namely i) new alluvial soil (NAS); ii) red lateritic soil (RS) and iii) black soil (BS) in the Indian subcontinent for determining the residues of pesticides from various chemical classes. To establish an effective pre-treatment process, an ethyl acetate-based extraction method with a freezing out cleanup step was employed. The analysis was performed using gas chromatographytandem mass spectrometry (GC-MS/MS). The validation experiments were performed on $220 \mathrm{GC}$-amenable pesticides by spiking all soil samples. The linearity of the calibration curves was satisfactory in matrix-matched standards and yielded the coefficients of determination $\left(R^{2}\right) \geq 0.99$ for approximately $98 \%$ of the target analytes in all matrices. At $10 \mathrm{ng} / \mathrm{g}$, the recoveries of the spiked pesticides were in the range of $70-120 \%$, with associated precision-RSD values $\leq 20 \%$ for approximately $85 \%, 88.6 \%$ and $89 \%$ of the compounds for BS, RS and NAS respectively. At the higher spiking levels of 20 and $50 \mathrm{ng} / \mathrm{g}$, average recoveries and RSDs readily met the validation criteria of all the studied pesticides. Overall, the method holds potential as a suitable procedure for multiresidue analysis in soils for safety evaluation and risk assessment purposes.

\section{Highlights}

- A multiresidue method is reported for simultaneous analysis of multiclass pesticides in soil

- The soil types represented the major crop growing areas of the Indian subcontinent

- Sample preparation involved extraction with ethyl acetate and cleanup by a freezing step

- The residues were estimated by gas chromatography tandem mass spectrometry

- The method sensitivity, accuracy and precision complied with the SANTE/12682/2019 guidelines

\section{Introduction}

Soil, a non-renewable natural component of our ecology, is the foundation of successful agriculture and human civilization. In modern agricultural practices, the application of pesticides has been unavoidable to increase crop productivity and quality. Pesticides are not only detrimental to human and animal health but also to the environment (EC 2007; Mondal et al. 2020; Asensio-Ramos et al. 2010). And, the widespread and indiscriminate use of pesticides has become a global concern with regard to food safety. Hence, it is of high interest to monitor residues of these pesticides in the soil to protect human health and the environment. For this, there is an interest in industrial and governmental sectors to develop accurate, easy, precise and cost-effective analytical methods.

In the past two decades, researchers have noted that the physico-chemical properties of soil and the nature of pesticides determine the types of interaction (persistence, fate, environmental behaviour and pollution risk) once a compound is introduced into soil (Andreu et al. 2004; Kah et al. 2007; Ahumeda et al. 2013). Soil is a heterogeneous complex matrix consisting of organic (humas $10-15 \%$, lipids, carbohydrates, lignin, flavonoids, pigments, resins and fulvic acids) and inorganic (variable percentage of sand, silt, and clay) components (Łozowicka et al. 2017). Because of the polar, non-polar and ionic activities of pesticides, they are often retained in the soil (Mondal et al. 2020), making residue analysis difficult. Besides, a pesticide is likely to be exposed to chemical as well as microbial degradation, producing metabolites of variable toxicological significance. Hence, a comprehensive risk assessment of a soil will necessitate analysis of these metabolites in conjunction with precursor molecules, complicating multiresidue analysis even more.

Over the past decade, many researchers have studied conventional and modern sample preparation methods for the determination of pesticide residues in soil (Naeeni et al. 2011; Rouvière et al. 2012; Guo and Lee 2013; Pastor-Belda et al. 2015; Ukalska-Jaruga et al. 2020). Several other communications have also been published on the application of QuEChERS-based methods in determining pesticides in soil matrices using GC-MS/MS (Yu et al. 2016; Jo et al. 2021), LCMS/MS (Caldas et al. 2011; Chen et al. 2019; Zaidon et al. 2019) and LC-QTOF/MS (Caria et al. 2021). For instance, Asensio-Ramos (2010) proposed a modified version of the QuEChERS method in three different soils (forestal, ornamental and agricultural, pH 4.2-5.9) by GC-MS/MS, in which they targeted only a few pesticides (majorly organophosphates with one thiadiazine). In another study, Leyva-Morales reported a pressurised liquid extraction (using dichloromethane: acetone, 50:50, v/v) method by GC coupled with an electron capture detector, a pulsed flame photometric detector and a thermionic specific detector (Leyva-Morales 2015). However, this method not only needed more time but also additional solvents, thus making it exceedingly expensive. The method also did not involve mass spectrometry based confirmation. Łozowicka et al. reported a QuEChERS method in a type of Polish soil (pH- 6.6, organic matter- $1.45 \%$, clay content- $2.43 \%$ ) that allowed them to analyse a wide range of compounds (216 pesticides), but it required a lengthy chromatographic run time of 41.88 min (Łozowicka et al. 2017). Thus, all of the reported studies have one or some more of the following drawbacks: the use of limited scope of analytes (Jo et al. 2021; Rouviere et al. 2012; Yu et al. 2016), high-priced and difficult analytical steps involved (Leyva-Morales 2015; Caria et al. 2021) or needed longer time for analysis (Łozowicka et al. 2017; Fernandes et al. 2013). To develop a method, we first tried a modified QuEChERS-based multiresidue method reported by Łozowicka et al. which studied a wide range of pesticides (Łozowicka et al. 2017). However, this method required a longer chromatographic runtime. We also recorded poor recoveries of several target pesticides with this method. Through literature surveys we concluded that there are scarcely any studies on the quantification and estimation of health risks associated with pesticide residues in Indian soils. All these knowledge gaps necessitate a new method, and we aimed to develop an effective multiresidue extraction method in three major agricultural soils (Balasubhramuniam 2017) of the Indian subcontinent. The performance of the method was verified by determining $220 \mathrm{GC}$-amenable pesticides from various chemical classes in three types of soils, namely new alluvial soil (NAS), red lateritic soil (RS) and black soil (BS). These soils were chosen because they have texturally diverse physicochemical properties and are also located in prime crop-growing areas. The method was thoroughly validated in terms of confirmatory identification and quantification. Overall, the method demonstrated the potential to be used as a suitable procedure for multiresidue analysis of pesticides in soils across laboratories for monitoring and risk assessment purposes.

\section{Experimental}




\section{Pesticide selection}

A total of 220 pesticides (GC amenable) from various chemical classes were chosen as they are widely relevant in today's agriculture and also demonstrate a range of physico-chemical properties (e.g., organochlorines, organophosphates, synthetic pyrethroids, heterocyclics and also their metabolites). Among them, some were reported as soil pollutants (Lozowicka et al. 2017) while others are banned or of restricted use, thus necessitating frequent monitoring [Indian Council of Agriculture Research (ICAR), Central Insecticides Board and Registration Committee (CIB \& RC), http://ppqs.gov.in/sites/default/files/list_of_pesticides_which_are_banned_refused_registration_and_restricted_in_use_as_on_30.06.2020.pdf] (Supplementary Table 1).

\subsection{Selection of test matrices, blank sample collection and sample preparation}

For the method development and validation, the following pesticide-free soil samples were collected from three different agro-climatic zones: new alluvial soil (NAS) from the University Research Station, Bidhan Chandra Krishi Viswavidyalaya (BCKV) (Mohanpur, district- Nadia, West Bengal), ii) red and lateritic soil (RS) from the Regional Research Station, BCKV (Jhargram, district- Midnapore, West Bengal) and iii) black soil (BS) from agricultural land (Pune, Maharashtra State). The physico-chemical properties of these soils are mentioned in Table 1.

Following the standard methodology of sampling, the soil samples were collected from the upper layer (between 15 and $20 \mathrm{~cm}$ of depth). The samples were air-dried, ground, passed through a $2 \mathrm{~mm}$ sieve, subsampled by the usual method of quartering and stored in zip-lock bags at $-20^{\circ} \mathrm{C}$. The sample collection, preservation and storage were based on the US EPA Method 1699. The physico-chemical properties of the soil samples were tested by the following methods: the hydrometer method for measuring the soil texture (Gee and Bauder 1986); the soil pH was measured after adding deionised water (1 + 2.5 by weight) (Jackson 1973) and the Walkley and Black wet oxidation method was used for determining the organic carbon content of the soil (Nelson and Soemmers 1982).

\section{Chemical reagents and materials}

The certified reference standards of $\geq 98 \%$ purity were purchased from Sigma-Aldrich (Steinheim, Germany) and Dr Ehrenstorfer GmbH (Augsburg, Germany).

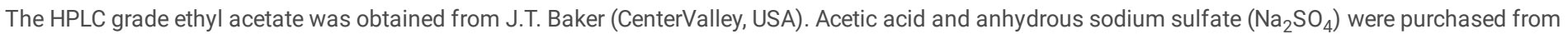
Merck (Bengaluru, India). The dispersive solid phase extraction (dSPE) sorbents [e.g. primary secondary amine (PSA) and $\mathrm{C}_{18}$ (end-capped)] were procured from Agilent Technologies (Santa Clara, CA, USA). The polytetrafluoroethylene (PTFE) syringe filters $(0.22 \mu \mathrm{m})$ were sourced from Chromatopak Analytical Instrumentation Pvt. Ltd. (Mumbai, India). The HPLC grade water was generated using a Sartorius water purification system (Gottingen, Germany).

\section{Apparatus}

At different stages of sample preparation, the following apparatus were used: a precision analytical balance (Adair Datt, ADGR 202, Mumbai, India), a pH meter (Thermo Orion, Chelmsford, MA, USA), an orbital shaker (Scigenics Instruments, Mumbai, India), vortex mixer (Genie 2T, Imperial Biomedicals, Mumbai, India), an ultrasonic bath (Oscar Electronics, Mumbai, India), a low-volume concentrator (TurboVap LV; Caliper Life Sciences, Russelsheim, Germany), a high speed refrigerated centrifuge (Kubota 6500, Kubota Corporation, Tokyo, Japan) and a micro-centrifuge (Dlab Instruments, Hyderabad, India).

\section{Preparation of standards}

The primary stock solutions of the individual pesticide standards were prepared by weighing $10( \pm 0.01)$ mg of each analyte in a volumetric flask (certified class ' $A$ ') and dissolving in $10 \mathrm{~mL}$ of ethyl acetate solvent and were stored in the dark at $-20 \pm 2{ }^{\circ} \mathrm{C}$. The intermediate standard mixture of $1 \mu \mathrm{g} / \mathrm{mL}$ was prepared using appropriate dilution and stored in the dark at $-20 \pm 2{ }^{\circ} \mathrm{C}$. During the entire study, the stability of the standards was monitored as per the SANTE guidelines (SANTE/12682/2019). By means of serial dilution of the intermediate mixture with ethyl acetate, the calibration standards $(0.002-0.05 \mu \mathrm{g} / \mathrm{mL}) \mathrm{were} \mathrm{prepared}$. For the matrix-matched standards preparation, the appropriate volume of pesticide-spiked mixture was added to the blank matrix extract.

\section{Instrumental parameters for GC-MS/MS analysis}

The sample analysis was performed using a gas chromatograph (GC 2010, Shimadzu Corporation, Kyoto, Japan) equipped with an AOC-20i auto-injector and hyphenated to a triple quadrupole tandem mass spectrometer (TQ8040, Shimadzu Corporation, Kyoto, Japan). Analytical separation of the target analytes was performed by using an Rxi®-5Sil MS (30 m $\times 0.25 \mathrm{~mm}, 0.25-\mu \mathrm{m}$ film thickness) column from Restek Corporation (Bellefonte, USA). In the splitless mode, 1 $\mu \mathrm{L}$ volume was injected. At a constant flow rate of $1.2 \mathrm{~mL} / \mathrm{min}$, ultra-pure grade helium was used as the carrier gas, while argon was used as the collision gas. The oven temperature was initially set to $90^{\circ} \mathrm{C}(1 \mathrm{~min})$, then gradually increased to $130{ }^{\circ} \mathrm{C}(3.71 \mathrm{~min})$ at a rate of $35^{\circ} \mathrm{C} / \mathrm{min}$, then to $240{ }^{\circ} \mathrm{C}(1 \mathrm{~min})$ at a rate of $10^{\circ} \mathrm{C} / \mathrm{min}$ and finally, from $15^{\circ} \mathrm{C}$ to $290^{\circ} \mathrm{C}(4 \mathrm{~min})$. This resulted in a total run time of $21.31 \mathrm{~min}$. The temperatures of the transfer line and the ion source were kept constant at 290 and $230^{\circ} \mathrm{C}$ respectively. The detector voltage was set at $0.70 \mathrm{kV}$. The solvent delay time was 1.5 min. The data acquisition, which started at $2 \mathrm{~min}$, was performed in the scan mode and multiple reaction monitoring (MRM) mode. In the MRM mode, the compound-specific m/z helped in the selective identification and quantification of each pesticide. To control the instrument and acquire and process data, the GC-MS LabSolutions ${ }^{\circledR}$ software (Version 4.45 SU2, Japan) was used. The method precision (repeatability) was checked as per the SANTE/12682/2019 guidelines.

\section{Optimisation of sample preparation}

In order to optimise an effective extraction method, we used our previous ethyl acetate-based extraction method on fruits and vegetables (Banerjee et al. 2007, 2012) with modifications. In our quest to develop a single concurrent extraction protocol, the sample preparation method was first optimised in the BS matrix and validated, and then extended to the other two soils, namely RS and NAS. BS has more clay and more organic carbon, both of which interact with 
pesticides and hold them through adsorption and absorption, and this could make the extraction relatively more difficult. For this, we decided to optimise the method in BS first. When BS demonstrated adequate recoveries, the remainder of the matrices were anticipated to follow suit. All experiments were carried out after homogenising the soils and passing them through a $2 \mathrm{~mm}$ sieve.

\section{Sample size optimisation}

To determine the effect of the sample size on the sensitivity, accuracy and precision, three different sample sizes (2, 5 and $10 \mathrm{~g})$ were selected. The samples were spiked at $0.1 \mathrm{mg} / \mathrm{kg}$ of the test analytes and extracted with $10 \mathrm{~mL}$ of distilled water and $10 \mathrm{~mL}$ of ethyl acetate in separate batches ( $\mathrm{n}=6$ ).

\section{Shaking versus sonication}

The effects of shaking and sonication were separately evaluated by keeping the samples on a shaker at a speed of 250 times/min for 10,20 and 30 min. In a parallel experiment, the samples were sonicated for 10, 20 and $30 \mathrm{~min}$. The recovery results were comparatively evaluated.

\section{Cleanup optimisation}

\section{Freezing}

To optimise the freezing temperature, a portion of the organic layer $\left(2 \mathrm{~mL}\right.$ ) of each tube was pipetted out and kept in a $15 \mathrm{~mL}$ centrifuge tube at $-20{ }^{\circ} \mathrm{C}$ (for 30 $\mathrm{min}$ and $60 \mathrm{~min}$ ) and $-80^{\circ} \mathrm{C}$ (for $10 \mathrm{~min}$ and $20 \mathrm{~min}$ ). The results were evaluated in terms of recoveries and matrix effects.

\section{Application of adsorbents in dSPE cleanup}

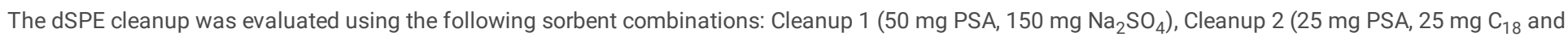
$150 \mathrm{mg} \mathrm{Na}_{2} \mathrm{SO}_{4}$ ) and Cleanup 3 ( $25 \mathrm{mg} \mathrm{PSA}, 50 \mathrm{mg} \mathrm{C}_{18}$ and $150 \mathrm{mg} \mathrm{Na}_{2} \mathrm{SO}_{4}$ ). Each tube was vigorously vortexed for 1 min before being centrifuged at 5600 $\times \mathrm{g}$ for $5 \mathrm{~min}$ at $4{ }^{\circ} \mathrm{C}$. The combined effect of the dSPE cleanup and freezing was also evaluated.

\section{Optimising the method}

For the recovery experiments, the pre-spiked soil was equilibrated for $20 \mathrm{~min}$ at room temperature. For extraction, a sample (5 g) was placed in a $50 \mathrm{~mL}$ polypropylene centrifuge tube and vortexed for $30 \mathrm{~s}$. Afterwards, $10 \mathrm{~mL}$ of distilled water was added to hydrate the matrix and handshaken for $30 \mathrm{~s}$. To it, 10 $\mathrm{mL}$ of ethyl acetate was added, followed by $10 \mathrm{~g}$ anhydrous $\mathrm{Na}_{2} \mathrm{SO}_{4}$. With no further delay, the resulting mixture was vigorously hand-shaken for $30 \mathrm{~s}$ and vortexed for $2 \mathrm{~min}$. The tubes were shaken at 250 times/min on a mechanical shaker for $20 \mathrm{~min}$, followed by centrifugation at $2800 \times \mathrm{g}$ for $10 \mathrm{~min}$. The clear supernatant was taken into a $15 \mathrm{~mL}$ centrifuge tube and held at $-80^{\circ} \mathrm{C}$ for $20 \mathrm{~min}$. After the phase separation, $2 \mathrm{~mL}$ of the organic extract was taken into another centrifuge tube, which was centrifuged at $11200 \times \mathrm{g}$ for $5 \mathrm{~min}$. The sample was filtered through a $0.22 \mu \mathrm{m}$ PTFE syringe filter and kept in an autosampler vial. Finally, the sample was injected into the GC-MS/MS.

\section{Validation of the developed method}

The method validation parameters such as accuracy, precision, linearity, specificity, ruggedness and matrix effect were evaluated as described in the SANTE/12682/2019 guidelines. These analytical performance parameters were evaluated by analysing all three types of soils, each spiked at three concentrations $(10,20$ and $50 \mathrm{ng} / \mathrm{g})$. Each experiment was performed in six replicates.

The linearity of the calibration curves was studied at a concentration that ranged between 2 and $40 \mathrm{ng} / \mathrm{g}$. The limit of quantification (LOQ) for each pesticide was determined as the lowest spiked concentration that could be quantified with satisfactory recoveries (70-120\%) and precision (an RSD of less than $20 \%$ ). The accuracy was estimated by recovery experiments (fortified at three-levels such as LOQ, $2 \times$ LOQ and $5 \times$ LOQ). The results were calculated using matrixmatched calibration standards, which were injected at the beginning as well as the end of every batch. The precision was expressed as within-the-laboratory repeatability in terms of the relative standard deviation (RSD). By involving three different analysts, the recovery experiments were conducted on three different days, showing intra-laboratory reproducibility.

The matrix effect (ME) was evaluated as signal suppression (\%) or enhancement (\%). The ME was determined by comparing the peak areas of the matrixmatched standards (peak areas of the post-extraction spike) with the corresponding peak areas of standards in solvent at $0.02 \mu \mathrm{g} / \mathrm{mL}$. According to Ferrer et al. the ME was classified into three categories as follows: soft (<20\%), medium (20-50\%) and strong matrix (more than 50\%) (Ferrer et al. 2011). The ruggedness of the method was confirmed by analysing a quality check/control (QC) sample (at $50 \mathrm{ng} / \mathrm{g})$ in every batch. In order to ensure the accuracy and precision of test results, analytical quality control criteria were applied. Each batch of samples was accompanied by the analysis of matrix blanks, spiked samples and matrix-matched calibration standards bracketing the real samples. One of the quality assurance measures was evaluated by confirming the reproducibility of analytical results. This was performed by the repeated determination of the spiked soil samples and the analysis of different analytical portions on different days and by employing different analysts. The results were evaluated with reference to the SANTE guidelines.

\section{Method comparison}

The method performance was compared to that of Łozowicka et al. method (Łozowicka et al. 2017) (discussed later in the result section).

\section{Method application in real-world samples}


Pesticide residues were evaluated in 25 field samples taken from various farms in Maharashtra and West Bengal states. Six replicates of each positive sample were examined and the precision-RSDs were estimated.

\section{Results And Discussion}

Because of the complexity of soil matrices, careful sample preparation was required to obtain a repeatable and sensitive multiresidue analysis. As mentioned earlier, the extraction efficiency of ethyl acetate was equivalent in comparison to other water-miscible solvents in different matrices.

\section{Sample size optimisation}

The sample size was optimised to ensure satisfactory recoveries. In practice, it is common to add a volume of water to dry samples prior to the extraction step (Rutkowska et al. 2018; Zhou et al. 2012). Next, the effect of sample size on method performance was evaluated. Almost all of the analytes provided an RSD of $<20 \%$ for a $2 \mathrm{~g}$ sample. The ME for $85 \%$ of the test analytes was less than $20 \%$. In addition, the initial residue was diluted, which lowered the quantification limit. This made the analysis of the incurred residues of the compounds difficult. For sample sizes of $5 \mathrm{~g}$ and $10 \mathrm{~g}$, the precision-RSDs were satisfactory $(<20 \%)$ for most of the analytes. But, when compared to a $5 \mathrm{~g}$ sample size, the ME was higher for approximately $22 \%$ of the compounds (including dichlorvos, atrazine, fenitrothion, profenofos, propargite, p,p'-DDT and pretilachlor) for a $10 \mathrm{~g}$ sample. As a result, $5 \mathrm{~g}$ was determined to be the best sample size for further research. The results of the sample size optimisation of selected pesticides (including early, mid and late eluting ones from different chemical classes) are presented in Figure $\mathbf{1} \mathbf{a}$ and $\mathbf{1 b}$.

\section{Shaking versus sonication}

When compared to sonication, shaking provided a better recovery percentage. As shown, 20 min of shaking time offered a better recovery (10-15\%) (Figure 2) in comparison to the shaking time of $10 \mathrm{~min}$. But, when this time was increased from 20 to $30 \mathrm{~min}$, no significant changes in the recovery were observed. Thus, a shaking time of 20 min was chosen.

\section{Optimisation of cleanup}

Without cleanup, $13 \%$ of the analytes showed recoveries higher than $130 \%$, while $26 \%$ of them exhibited a significant ME (above $50 \%$ ). This indicated that the cleaning up of the soil extract was necessary to minimise the ME.

\section{Optimisation of freezing temperature}

The main fraction of the soil matrix is humus, which mainly comprises organic acids and their conjugate bases, and $20 \%$ of soil humas occurs in the form of lipids (Kononova 1966; Morrison 1969). Because of their high solubility in ethyl acetate, these lipids might get co-extracted with the target pesticide residues. By putting the extracts at $-80^{\circ} \mathrm{C}$ for $20 \mathrm{~min}$, the GC-MS full scan mode analysis revealed that a large extent of matrix-derived compounds were reduced (Supplementary Figure 1). A longer span of freezing (20 min, $30 \mathrm{~min}$ and 1 hour, at $-20^{\circ} \mathrm{C}$ ) affected the recoveries of some of the organochlorine pesticides in BS. The successful recovery of $86.7 \%$ of the tested pesticides demonstrated the effectiveness of this cleanup step. The ion ratio (the qualitative to quantitative MRMs, \%) deviations (with the matrix matched standards) of some compounds (e.g. dichlorvos and parathion) did not comply with the accepted criteria $(<30 \%)$ due to higher matrix effects, resulting in their false negative detection. Such false detection issues were resolved by performing the freezing step (Supplementary Figure 2a, 2b). Additionally, the peak shape of a number of compounds (e.g. chlorothalonil, oxyfluorfen, chlorfenapyr and fipronil) was improved with the freezing step (Supplementary Figures 3a, 3b, 3c, 3d).

\section{dSPE cleanup optimisation}

A separate cleanup experiment with different dSPE sorbents was also evaluated. The Cleanup 1 strategy included only PSA, which increased the pH of the BS extract ( $\mathrm{pH}-7.8)$. As seen, satisfactory results were obtained for only $71 \%$ of the target analytes. The recoveries were unsatisfactory for the remaining analytes (mostly the base sensitive compounds), keeping their recoveries between $60-70 \%$ and $120-140 \%$. The precision-RSDs were mostly < $20 \%$. A lower recovery for a few herbicides (e.g. fluzifop-p-butyl, clomazone, propanil) might be due to their reaction with the dSPE sorbents (Lehotay 2007; Niell et al. 2009). Hence, for Cleanup 2, the amount of PSA was reduced and combined with $\mathrm{C}_{18}$. This provided satisfactory results for $84.8 \%$ of the analytes. The Cleanup 3 , which had an enhanced amount of $\mathrm{C}_{18}$, was effective in binding and removing the starch and sugar co-extractives, also reported earlier by Caldas et al. 2011. The results were comparable to Cleanup 2 and Cleanup 3. Therefore, we chose Cleanup 2 as the optimum sorbent combination for the dSPE cleanup.

\section{Combined effect of freezing and dSPE cleanup}

When the effectiveness of Cleanup 2 was estimated, almost $83.3 \%$ of the analytes demonstrated a recovery range of $70-120 \%$, which was much lower than the percentage of the analytes obtained only in the case of the freezing step without dSPE cleanup. For example, a significant number of compounds, for example, chlorfenapyr, tetrachlorvinphos, triazophos and tricyclazole, suffered from poor recoveries of $<30 \%$ when the cleanup sorbents were used. The results showed that freezing at $-80^{\circ} \mathrm{C}$ for 20 min (without a dSPE cleanup) recovered the highest number of compounds (Figure 3a) within the acceptable range of $70-120 \%$. The use of freezing plus dSPE cleanup did not have a significant effect on the recovery of pesticides from the extracts. The absence of a dSPE cleanup step is also observed in the study by Rutkowska et al. $\mathbf{2 0 1 8}$ for dry herb samples, although Caldas et al. obtained better results for multiclass pesticides in the soil samples under paddy cultivation (Caldas et al. 2011). In another study on herbicides in soil, Zhou et al. noted even a better recovery for pyrazosulfuran ethyl with a normal extraction over PSA or $\mathrm{C}_{18}$ (Zhou et al. 2012). The recovery data of some compounds including allidochlor, dichlobenil, chlorthalonil, biphenyl, ethion, mevinphos, paclobutrazole, phorate, profenofos, tau- fluvalinate, trans-chlordane, tricyclazole and 2,3,5,6 tetrachloro aniline supporting this fact are presented in Figure $3 \mathrm{~b}$. Compared to the extraction method using the dSPE cleanup step, this method was more cost-effective as it 
involved fewer solvents and reagents (excluding expensive phase PSA and $\mathrm{C}_{18}$ ). Besides, the current study was less laborious as it did not require a partitioning method or the weighing of cleanup reagents.

\section{Method validation}

All the tested pesticides could be selectively estimated in a single GC run of $21.31 \mathrm{~min}$. Dichlorvos was the earliest compound ( $t_{R}=4.44$ min), while fenvalerate $\left(t_{R}=21.04 \mathrm{~min}\right)$ was the last one in the chromatogram. The GC programme provided chromatographic separation of the pyrethroid isomers and facilitated their accurate quantification as observed for cyfluthrin [alpha- $\mathrm{HCH}\left(t_{R}=9.303 \mathrm{~min}\right)$, beta- $\mathrm{HCH}\left(t_{R}=9.918 \mathrm{~min}\right)$, gamma- $\mathrm{HCH}\left(t_{R}=9.985 \mathrm{~min}\right)$ and delta- $\mathrm{HCH}\left(t_{R}\right.$ $=10.584 \mathrm{~min})$, cyfluthrin-I ( $\left.t_{R}=19.117 \mathrm{~min}\right)$, cyfluthrin-II ( $\left.t_{R}=19.234 \mathrm{~min}\right)$, cyfluthrin-III $\left(t_{R}=19.307 \mathrm{~min}\right)$ and cyfluthrin-IV ( $\left.\left.t_{R}=19.357 \mathrm{~min}\right)\right]$ and cypermethrin [cypermethrin-I $\left(t_{R}=19.501 \mathrm{~min}\right)$, cypermethrin-II ( $\left.t_{R}=19.633 \mathrm{~min}\right)$, cypermethrin-III $\left(t_{R}=19.705 \mathrm{~min}\right)$ and cypermethrin-IV ( $\left.t_{R}=19.762 \mathrm{~min}\right)$ ]. The quantitative results in three soil matrices are presented in Table 2. The validation of this optimised analytical method was evaluated by different parameters including linearity (expressed as $\mathrm{R}^{2}$ ), LOQ, ME, accuracy (expressed as recovery) and precision (expressed as RSD) (SANTE/12682/2019).

A good linearity $\left(R^{2} \geq 0.99\right)$ was obtained in the calibration curve for all compounds over a concentration range of 2-40 $\mathrm{ng} / \mathrm{g}$. A slightly lower $\mathrm{R}^{2}$ value ( 0.98) was noted for fipronil (BS), hexachlorobenzene (NAS), cypermethrin (RS) and permethrin (RS). In the case of BS, a considerable ME was mainly observed for phenylureas (e.g. linuron), aromatic ethers (e.g. oxyfluorfen), polychlorobenzene (e.g. hexachlorobenzene), monosubstituted with nitro- (e.g. quintozene) and dinitrile (e.g. chlorothalonil) group, the mid-eluting organophosphates (e.g. phoratesulfide, tolclofos methyl chlorfenvinphos etc.) and late-eluting synthetic pyrethroids (e.g. cypermethrin etc.) compounds (Supplementary Figure 4).

According to the findings, $69 \%$ of the compounds had a lower ME ( $\pm 20 \%$ ) in BS, while 59 pesticides showed a medium ME (ranged from 21 to $49 \%$ ). Among all, only 9 pesticides including tolcofos methyl, phorate sulfide, linuron, $4^{\text {th }}$ peak of cypermethrin eluting at $19.762 \mathrm{~min}$, delta-HCH, endosulfan sulfate, etridazole, oxyfluorfen and parathion showed a stronger ME of $\geq 50 \%$. Tolcofos methyl showed the greatest ME value of $78.39 \%$. In the RS soil type, $83 \%$ of pesticides showed a lower ME; 33 pesticides had values ranging from \pm 21 to $\pm 49 \%$. Four pesticides including alpha-endosulfan, chlorothalonil, fenvalerate and tatradifon exhibited signal enhancements of $>50 \%$. Tolcofos methyl showed the greatest ME value of $78.4 \%$ in RS. A signal suppression was observed only for (E)-chlorfenvinfos in BS as well as RS. Whereas in NAS, $90 \%$ of compounds showed no ME. A moderate ME was observed for 17 compounds excluding chlorpyrifos, alpha-endosulfan and oxyfluorfen, which had a higher ME. The ME of some selected pesticides is presented in Supplementary Figure

4.

The ME was lowered by applying the freezing step. A considerable ME of the same or different compounds was also observed previously in soil matrices. For instance, Fernandes et al. 2013 reported high MEs for 12 pesticides, which included alpha- and beta-HCH, HCB, o,p-DDT, bupirimate, chlorpyrifos, fludioxonil, malathion, methiocarb and pendimetaline. In another study, Asensio-Ramoset et al. reported a significant ME for 11 pesticides, namely buprofezin, chlorpyrifos, chlorpyrifos-methyl, diazinon, dimethoate, ethoprofos, fenirothion, malaoxon, malathion and phosmet (Asensio-Ramoset et al. 2010). According to Łozowicka et al. positive MEs (signal enhancement) were reported for alpha-endosulfan, beta-endosulfan, endosulfan sulfate, dichlorvos, methamidophos, oxyflurofen and oxamyl, whereas negative MEs (signal suppression) were observed in the cases of bupirimate, dichlobenil, etaconazole, propham and trifloxystrobin ( Łozowicka et al. 2017). Therefore, to correct the recoveries, in our study, the matrix-matched calibration graphs (soil type-specific) were used for quantification. This approach adjusted the accuracies within the acceptable range of $70-120 \%$.

At the lowest fortification level of $10 \mathrm{ng} / \mathrm{g}, 85 \%$ of the analytes demonstrated satisfactory method performance (recoveries ranged within $70-120 \%$ with a $<20 \%$ RSD). The LOQ for these compounds was set at $10 \mathrm{ng} / \mathrm{g}$. At this LOQ level of $10 \mathrm{ng} / \mathrm{g}, 11$ chemicals, including p,p'-DDT, p,p'-DDD, p,p'-DDE, o,p'-DDE, o,p'DDT, hexachloro-exo-epoxide, cypermethrin-1, aldrin and others, showed a recovery of between 60 and $69 \%$ and a reasonable precision RSD of $10 \%$. For example, transfluthrin, trans nonachlor, trans permethrin, linuron, fluchloralin and the third isomeric peak of cypermethrin (eluting at 19.703) showed around $60 \%$ of recoveries. The precision RSD in each case was $<20 \%$. The only exception was trans-nonachlor, which had a poor precision-RSD at $10 \mathrm{ng} / \mathrm{g}$ (above $20 \%$ ). At $20 \mathrm{ng} / \mathrm{g}$, however, a satisfactory result was achieved for all these pesticides. Only a handful of compounds, for instance, fenitrothion, propoxur, taufluvalinate and azinphos ethyl, showed recoveries of more than $120 \%$, although their precision-RSDs were $<10 \%$. At the fortification level of $20 \mathrm{ng} / \mathrm{g}$, all these analytes complied with the method performance criteria (Table 2).

In a previous study, certain compounds, for example, aldrin, tolyfluanid, dichlofluanid, dieldrin, fipronil, propargite, profenofos, chlorothalonil, p,p'-DDT, lambdacyhalothrin, pyriproxyfen, diazinon, oxadiazon and edifenphos, demonstrated poor recoveries (Walorczyk et al. 2012). In our earlier study conducted on animal feed, a poor recovery was also experienced for these compounds (Kumar et al. 2020). However, the recoveries and precision of these compounds were satisfactory in this study (highlighted in bold, Table 2). Our results showed non-detection of allethrin, flucythrinate, phenothrin, tetramethrin, cycloate, endrin and paraoxon methyl in BS. Some compounds did not meet the identification criteria of the ion ratio matching (within $\pm 30 \%$ ), especially at lower concentrations where isobaric interferences from co-eluting matrix compounds might alter the value and result in non-detection (Walorczyk et al. 2012) (Figure 4a). Another reason for false negatives in the case of some compounds (e.g. paraoxon methyl, cycloate and endrin) might be because of their recovery loss in the sample preparation stage. The degradation of cycloate, a thiocarbamate ester, might have occurred due to alkaline hydrolysis. For paraoxon methyl, the breakdown could have been due to the oxidation of mixed mineral oxides present in the soil matrix (Zimmermann et al. 2013).

The method performance was evaluated in the remaining soils, namely NAS and RS. As illustrated in Figure $\mathbf{4 b}$ and Figure $\mathbf{4 c}$, a few compounds, for instance, boromophos ethyl, chlorobenzilate, hexachlorobenzene, propanil, myclobutanil and nitrofen in NAS and bromofenvinphos, cis-permethrin, etofenprox, phenothrin and tetramethrin in RS, were not detected. In the NAS matrix, $89 \%$ of pesticides satisfied the method validation criteria laid out in the SANTE/12682/2019 guidelines, with the associated recoveries within 70-120\% and precision RSD $\leq 20 \%$ at the LOQ of $10 \mathrm{ng} / \mathrm{g}$. Among all, only prochloraz and ethalfluralin suffered from a poor recovery of $<60 \%$, with an associated precision RSD $\leq 20 \%$. However, at a $20 \mathrm{ng} / \mathrm{g}$ level, their recoveries were satisfactory. 
In RS, which is also an acidic matrix, this proportion was decreased to $~ 88.63 \%$. Both beta-endosulfan (a sulfite ester) and EPN (a phosphonic ester) suffered from poor recoveries even in this acidic soil at 10 and $20 \mathrm{ng} / \mathrm{g}$. Nevertheless, the recoveries were obtained in the range of $70-120 \%$ for the majority of pesticidematrix combinations. In all matrices, a similar group of problematic compounds was observed with recovery values ranging from 60 to $130 \%$ with a consistent $\leq 20 \%$ RSD (Table 2, highlighted in bold, Supplementary Figure 5).

When calculating against different calibration curves, agreeable quantification results were obtained, which clearly indicated the satisfactory reproducibility and ruggedness of this method (Supplementary Table 2). The repeatability (intra-day precision) and reproducibility (inter-day precision) RSD values were $<20 \%$ for all the target analytes. Besides, 30 continuous injections of the post-extraction spiked samples at $50 \mathrm{ng} / \mathrm{g}$ provided the RSD values $<7 \%$ for all the target compounds, indicating good instrument repeatability (Supplementary Table 2).

\section{Method throughput}

Following GC-MS/MS analysis, four batches of the extracted samples (48 in number) could be acquired in a 24-hour cycle. This facilitated a high throughput residue analysis. For all the target compounds in all matrices, the output of this method was also economically viable with regard to time and productivity.

\section{Applications in real-life situations}

In the real soil samples, six different pesticides viz, dichlorvos, biphenyl, diphenylamine, anthraquinone, tricylazole and chlorpyrifos were detected (Supplementary Table 3). A repeat-extraction did not result in any additional recovery of residues. In all cases, the precision-RSDs were highly satisfactory $(\mathrm{RSD},<10 \%, \mathrm{n}=6)$.

\section{Comparison with other methods}

As previously stated, the ethyl acetate-based method is widely used in pesticide residue analysis, particularly for vegetables and fruits. However, no previous applications of this method have been reported on soil. So, in this study, 220 pesticides were analysed in three different types of soil using a GC-MS/MS instrument in a single chromatographic run time of 21.31 minutes. The previous works required a longer run time (e.g. $41.88 \mathrm{~min}$ or $25 \mathrm{~min}$ ), had a limited number of pesticides (e.g. 34, 58, 123 and 216 compounds) in scope or matrices (specific soil, no wider pH range). In comparison to the QuEChERS method, the ethyl acetate extraction provided superior recoveries for the traditionally low-recovery compounds, as described in section 3.4. However, in our study, the absence of a dSPE cleanup step might have resulted in better recoveries. When some compounds were extracted with acetonitrile as done in the QuEChERS method, the results pertaining to chlorobenzenes (RSD ranged between 26 and 41\%), chlorophenols (RSD ranged between 21-35\%) and HCH isomers (RSDs for alpha, beta, delta, gamma were 25, 31, 37 and $29 \%$ respectively) were less repeatable. These observations were also supported by an earlier study by Rouviere et al. (Rouviere et al. 2012). However, the ethyl acetate-based method here showed satisfactory and consistent recovery of the above-mentioned compounds with satisfactory precision RSDs of $\leq 20 \%$ (Table 2 ) in all the three soil matrices.

\section{Conclusions}

In this study, the conventional ethyl acetate-based extraction method in three different types of Indian soils was applied, although with certain modifications. The various steps that affect the extraction were optimised for $220 \mathrm{GC}$ amenable pesticides (different chemical classes). The developed method was validated in three texturally different soils (covering a wide range of $\mathrm{pH}$ between 5.5 and 7.8 ).

In all of the soil matrices, the method provided satisfactory performance. Clean extracts were obtained using the optimised approach, which did not require any dispersive SPE cleanup. The cost of analysis was reduced because PSA was not necessary. However, it is worthwhile to devote time to optimising analytical processes in order to improve technique performance. The majority of the target compounds met the validation criteria, with recoveries ranging from 70 to $120 \%$ and RSDs less than or equal to $20 \%$. Additionally, the chromatographic technique produced well-defined and well-shaped peaks in a short amount of time. As the method demonstrated high precision for incurred residues, it appears fit for purpose and hence is recommended for regulatory soil testing purposes across laboratories.

\section{Declarations}

\section{Ethical approval}

Not applicable.

\section{Consent to participate}

Not applicable.

\section{Consent for publish}

Not applicable.

\section{Author contributions}

$\mathrm{AB}$ and $\mathrm{KB}$ contributed to the study conception and design, and drafted the manuscript. $\mathrm{AB}$ performed sample preparation and data analysis. $\mathrm{AP}$ and $\mathrm{AN}$ performed the GC-MS/MS analysis. All authors read and approved the final manuscript. 


\section{Funding}

The authors declare that no funds, grants, or other support were received during the preparation of this manuscript.

\section{Competing interests}

The authors declare no competing and conflict of interest.

\section{Availability of data and material}

All data are available with the institute repository.

\section{References}

1. Andreu V, Picó Y (2004) Determination of pesticides and their degradation products in soil: critical review and comparison of methods. TrAC Trends Anal Chem 10-11:772-789. http://dx.doi.org/10.1016/j.trac.2004.07.008

2. Asensio-Ramos M, Hernández-Borges J, Ravelo-Pérez LM, Rodriguez-Delgado MA (2010) Evaluation of a modified QuEChERS method for the extraction of pesticides from agricultural, ornamental and forestal soils. Anal Bioanal Chem 396:2307-2319. https://doi.org/10.1007/s00216-009-3440-2

3. Balasubramanian A (2017) Technical reports on Soils of India 1-43. http://dx.doi.org/10.13140/RG.2.2.20739.81448

4. Banerjee K, Oulkar DP, Dasgupta S, Patil SB, Patil SH, Savant R, Adsule PG (2007) Validation and uncertainty analysis of a multi-residue method for pesticides in grapes using ethyl acetate extraction and liquid chromatography-tandem mass spectrometry. J Chromatogr A 1173(1-2):98-109. https://doi.org/10.1016/j.chroma.2007.10.013

5. Banerjee K, Utture S, Dasgupta S, Kandaswamy C, Pradhan S, Kulkarni S, Adsule P (2012) Multiresidue determination of 375 organic contaminants including pesticides, polychlorinated biphenyls and polyaromatic hydrocarbons in fruits and vegetables by gas chromatography-triple quadrupole mass spectrometry with introduction of semi-quantification approach. J Chromatogr A 1270:283-295. https://doi.org/10.1016/j.chroma.2012.10.066

6. Caldas SS, Bolzan CM, Cerqueira MB, Tomasini D, Furlong EB, Fagundes C, Primel EG (2011) Evaluation of a modified QuEChERS extraction of multiple classes of pesticides from a rice paddy soil by LC-APCl-MS/MS. J Agric Food Chem 59(22):11918-11926. https://doi.org/10.1021/jf202878s

7. Caria G, Proix N, Mougin C, Ouddane B, Net S (2021) A new, simple, efficient and robust multi-residue method based on pressurised-liquid extraction of agricultural soils to analyze pesticides by liquid chromatography coupled with a high resolution quadrupole time-of-flight mass spectrometer. Int $\mathrm{J}$ Environ Anal Chem 1-16. http://dx.doi.org/10.1080/03067319.2021.1889531

8. Chen Y, Yu Y, Liu X, Yang Y, Lu P, Hu D (2019) Development and validation of a liquid chromatography-tandem mass spectrometry method for multiresidue determination of 25 herbicides in soil and tobacco. chromatographia 83(2). https://doi.org/10.1007/s10337-019-03834-6

9. CIB RC (2018) Major uses of pesticides. Updated on May. http://ppqs.gov.in/divisions/cib-rc/major-uses-of-pesticides

10. Diego A, Ahumada, Luis A, Ariasb, Carlos R, Bojacác (2013) Multiresidue determination and uncertainty analysis of pesticides in soil by ultrafast liquid chromatography coupled to mass spectrometry. J Braz Chem Soc 24(7):1188-1197. http://dx.doi.org/10.5935/0103-5053.20130153

11. EC (2007) : The use of plant protection products in the European Union Data 1992-2003 2007 edition. Luxembourg: Office for Official Publications of the European Communities. https://ec.europa.eu/eurostat/web/products-statistical-books/-/KS-76-06-669

12. Fernandes VC, Domingues VF, Mateus N, Delerue-Matos C (2013) Multiresidue pesticides analysis in soils using modified QuEChERS with disposable pipette extraction and dispersive solid-phase extraction. J Sep Sci 36(2):376-382. https://doi.org/10.1002/jssc.201200673

13. Ferrer C, Lozano A, Agüera A, Girón AJ, Fernández-Alba AR (2011) Overcoming matrix effects using the dilution approach in multiresidue methods for fruits and vegetables. J Chromatogr A 1218(42):7634-7639. https://doi.org/10.1016/j.chroma.2011.07.033

14. Gee GW, Bauder JW, Klute A (eds) (1986) Methods of soil analysis: Part-1- Physical and mineralogical methods,pp 383-409. Madison:American Society of Agronomy. https://doi.org/10.2136/sssabookser5.1.2ed.c15

15. Guo L, Lee HK (2013) Microwave assisted extraction combined with solvent bar microextraction for one-step solvent-minimized extraction, cleanup and preconcentration of polycyclic aromatic hydrocarbons in soil samples. J Chromatogr A 1286:9-15. https://doi.org/10.1016/j.chroma.2013.02.067

16. Jackson ML (1985) Soil chemical analysis. 11th printing by the author. Dept. of Soil Science, University of Wisconsin, Madison, WI 489. https://soils.wisc.edu/wp-content/uploads/2013/10/JacksonOrderForm1.pdf

17. Jo HW, Park MG, Jeon HJ, Moon JK, Lee SE (2021) Analysis of multiresidue pesticides in agricultural paddy soils near industrial areas in Korea by GCMS/MS and LC-MS/MS Using QuEChERS extraction with dSPE clean-up. Appl Sci 11(18):8415. https://doi.org/10.3390/app11188415

18. Kah M, Beulke S, Brown CD (2007) Factors influencing degradation of pesticides in soil. J Agric Food Chem 55(11):4487-4492. https://doi.org/10.1021/jf0635356

19. Kononova MM (1966) Soil organic matter, 2nd English Tr. by T. Z. Novakowski and A. C. D. Newman. Pergamon Press, Inc, Oxford. https://www.elsevier.com/books/soil-organic-matter/kononova/978-0-08- 011470-5

20. Kumar A, Bhattacharyya A, Shinde R, Dhanshetty M, Elliott CT, Banerjee K (2020) Development and validation of a multiresidue method for pesticides and selected veterinary drugs in animal feed using liquid-and gas chromatography with tandem mass spectrometry. J Chromatogr A 461416. https://doi.org/10.1016/j.chroma.2020.461416

21. Lehotay SJ (2007) Determination of pesticide residues in foods by acetonitrile extraction and partitioning with magnesium sulfate: collaborative study. $J$ AOAC Int 90(2):485-520. https://pubmed.ncbi.nlm.nih.gov/17474521/ 
22. Leyva-Morales JB, Valdez-Torres JB, Bastidas-Bastidas PJ, Betancourt-Lozano M (2015) Validation and application of a multi-residue method, using accelerated solvent extraction followed by gas chromatography, for pesticides quantification in soil. J Chromatogr Sci 53(10):1623-1630.

https://doi.org/10.1093/chromsci/bmv063

23. Łozowicka B, Rutkowska E, Jankowska M, GC/ECD/NPD (2017) Influence of QuEChERS modifications on recovery and matrix effect during the multiresidue pesticide analysis in soil by GC/MS/MS and. Environ Sci Pollut Res 24(8):7124-7138. https://doi.org/10.1007/s11356-016-8334-1

24. Mondal P, Rakshit A, Ghosh S, Chakraborty S, Philip V, Datta A (2020) Soil Analysis: recent trends and applications modern sample preparation techniques for pesticide residues analysis in soil. Springer Nature Singapore Pte Ltd 163-186. https://doi.org/10.1007/978-981-15-2039-6

25. Morrison RI (1969) Soil lipids. In Organic geochemistry Springer, Berlin, Heidelberg. 558-575. https://link.springer.com/chapter/10.1007/978-3-642-877346_29

26. Naeeni MH, Yamini Y, Rezaee M (2011) Combination of supercritical fluid extraction with dispersive liquid-liquid microextraction for extraction of organophosphorus pesticides from soil and marine sediment samples. J Supercrit Fluids 57(3):219-226. https://doi.org/10.1016/j.supflu.2011.03.005

27. Nelson DW, Sommers L (1983) Total carbon, organic carbon, and organic matter. Methods of soil analysis: Part 2 chemical and microbiological properties 9:539-579. https://doi.org/10.2134/agronmonogr9.2.2ed.c29

28. Niell S, Pareja L, Geis Asteggiante L, Cesio MV, Heinzen H (2010) Comparison of extraction solvents and conditions for herbicide residues in milled rice with liquid chromatography-diode array detection analysis (LC-DAD). Food Addit Contam 27(2):206-211. https://doi.org/10.1080/19440040903296246

29. Pastor-Belda M, Garrido I, Campillo N, Viñas P, Hellín P, Flores P, Fenoll J (2015) Dispersive liquid-liquid microextraction for the determination of new generation pesticides in soils by liquid chromatography and tandem mass spectrometry. J Chromatogr A 1394:1-8. https://doi.org/10.1016/j.chroma.2015.03.032

30. Rouvière F, Buleté A, Cren-Olivé C, Arnaudguilhem C (2012) Multiresidue analysis of aromatic organochlorines in soil by gas chromatography-mass spectrometry and QuEChERS extraction based on water/dichloromethane partitioning. Comparison with accelerated solvent extraction. Talanta 93:336344. https://doi.org/10.1016/j.talanta.2012.02.048

31. Rutkowska E, Łozowicka B, Kaczyński P (2018) Modification of multiresidue QuEChERS protocol to minimize matrix effect and improve recoveries for determination of pesticide residues in dried herbs followed by GC-MS/MS. Food Anal. Methods 11(3):709-724.

https://link.springer.com/article/10.1007/s12161-017-1047-3

32. SANTE/12682 (2019) /https://www.eurlpesticides.eu/userfiles/file/EurlALL/AqcGuidance_SANTE_2019_12682.pdf, accessed 7 February 2020

33. Ukalska-Jaruga A, Smreczak B, Siebielec G (2020) Assessment of pesticide residue content in Polish agricultural soils. Molecules 25(3):587. https://www.mdpi.com/1420-3049/25/3/587

34. USEPA (1699): US Environmental Protection Agency. Pesticides in Water, Soil, Sediment, Biosolids, and Tissue by HRGC/HRMS, https://www.epa.gov/sites/production/files/201510/documents/method_1699_2007.pdf accessed 29.07.2020

35. Walorczyk S, Drożdżyński D (2012) Improvement and extension to new analytes of a multi-residue method for the determination of pesticides in cereals and dry animal feed using gas chromatography-tandem quadrupole mass spectrometry revisited. J Chromatogr A 1251:219-231.

https://doi.org/10.1016/j.chroma.2012.06.055

36. Yu Y, Liu X, He Z, Wang L, Luo M, Peng Y, Zhou Q (2016) Development of a multi-residue method for 58 pesticides in soil using QuEChERS and gas chromatography-tandem mass spectrometry. Anal Methods 8(11):2463-2470. https://pubs.rsc.org/en/content/articlelanding/2016/AY/C6AY00337K

37. Zaidon SZ, Ho YB, Hamsan H, Hashim Z, Saari N, Praveena SM (2019) Improved QuEChERS and solid phase extraction for multi-residue analysis of pesticides in paddy soil and water using ultra-high performance liquid chromatography tandem mass spectrometry. Michrochem $\mathrm{J} 145: 614-621$. https://doi.org/10.1016/j.microc.2018.11.025

38. Zhou X, Zeng D, Wang Y, Tian H, Bai L, Tan H, Du L (2012) QuEChERS extraction for high performance liquid chromatographic determination of pyrazosulfuron-ethyl in soils. J Chem Soc Pak 34(6):28. https://jcsp.org.pk/ArticleUpload/3937-19472-1-CE.pdf

39. Zimmermann LM, Almerindo GI, Mora JR, Bechtold IH, Fiedler HD, Nome F (2013) Degradation of methyl paraoxon in the presence of $\mathrm{Mg}^{2+}{ }_{-} \mathrm{Al}^{3+}$ mixed oxides. J Phys Chem C 117(49):26097-26105. https://doi.org/10.1021/jp408788a

\section{Tables}

Table 1. Physico-chemical characteristics of the soils

\begin{tabular}{|llll|}
\hline Physico-chemical properties & RS & NAS & BS \\
\hline Soil order & Aridisol & Mollisol & Vertisol \\
Location & Jhargram & Mohanpur & Pune \\
$\mathrm{pH}$ & 5.45 & 7.02 & 7.8 \\
\hline Organic Carbon (\%) & 0.64 & 1.00 & 0.67 \\
\hline Sand (\%) & 54 & 12 & 16 \\
\hline Silt (\%) & 16 & 65 & 24 \\
\hline Clay (\%) & 30 & 23 & 60 \\
\hline
\end{tabular}


Table 2

Method validation results [Recovery (Rec \%) and Precision (RS

\begin{tabular}{|c|c|c|c|c|c|c|c|c|c|}
\hline \multirow{3}{*}{$\begin{array}{l}\text { Sr. } \\
\text { No. }\end{array}$} & \multirow[t]{3}{*}{ Compound Name } & \multirow{3}{*}{$\begin{array}{l}\text { RT } \\
(\min )\end{array}$} & \multicolumn{4}{|c|}{ Black Soil } & \multicolumn{3}{|c|}{ New Alluvial Soil } \\
\hline & & & \multicolumn{2}{|c|}{10 ng/kg } & \multicolumn{2}{|l|}{$20 \mathrm{ng} / \mathrm{kg}$} & \multicolumn{2}{|l|}{10 ng/kg } & \multirow{2}{*}{$\frac{2}{\mathrm{R}}$} \\
\hline & & & $\operatorname{Rec} \%$ & RSD & $\operatorname{Rec} \%$ & RSD & $\operatorname{Rec} \%$ & RSD & \\
\hline 1 & (E)-Chlorfenvinphos & 12.762 & 110.00 & 18.99 & 120.00 & 16.48 & 84.25 & 15.11 & 9: \\
\hline 2 & (Z)-Chlorfenvinphos & 12.839 & 92.03 & 16.93 & 109.37 & 3.05 & 107.78 & 0.98 & 9 \\
\hline 3 & $\begin{array}{l}\text { 1,1-Dichloro-2,2-bis(4- } \\
\text { ethylphenyl)ethane }\end{array}$ & 14.632 & 75.65 & 11.24 & 88.74 & 4.04 & 66.70 & 8.57 & 6 \\
\hline 4 & $\begin{array}{l}\text { 2,3,5,6- } \\
\text { Tetrachloroaniline }\end{array}$ & 8.519 & 75.74 & 19.74 & 81.93 & 3.11 & 94.06 & 7.20 & 81 \\
\hline 5 & 2,4'-Methoxychlor & 15.914 & 74.50 & 4.52 & 80.88 & 5.38 & 103.47 & 19.86 & 91 \\
\hline 6 & 2-Phenylphenol & 7.365 & 82.51 & 9.28 & 94.87 & 1.09 & 88.00 & 6.67 & 81 \\
\hline 7 & 3,4-Dichloroaniline & 6.444 & 85.25 & 19.21 & 77.90 & 2.98 & 83.36 & 6.50 & 81 \\
\hline 8 & 4 Bromo 2 Chlorophenol & 4.787 & 85.40 & 9.19 & 97.84 & 2.96 & 96.62 & 6.42 & 91 \\
\hline 9 & $\begin{array}{l}4 \text { chloro } 3 \text { methyl } \\
\text { phenol }\end{array}$ & 4.996 & 96.85 & 7.79 & 103.46 & 1.90 & 96.36 & 11.63 & 91 \\
\hline 10 & $\begin{array}{l}\text { 4,4'- } \\
\text { Dichlorobenzophenone }\end{array}$ & 12.347 & 86.37 & 7.78 & 113.96 & 4.16 & 93.81 & 8.25 & 9 \\
\hline 11 & 4,4'-methoxychlor olefin & 15.547 & 73.12 & 11.17 & 101.34 & 3.07 & 84.67 & 14.47 & $8^{\prime}$ \\
\hline 12 & Acetochlor & 11.043 & 89.41 & 17.16 & 103.25 & 2.64 & 88.27 & 19.44 & $9 !$ \\
\hline 13 & Acrinathrin-2 & 17.866 & 76.72 & 12.80 & 114.81 & 2.57 & 115.22 & 6.79 & 8 . \\
\hline 14 & Alachlor & 11.221 & 96.34 & 5.19 & 98.48 & 3.81 & 103.30 & 5.98 & $8 !$ \\
\hline 15 & Aldrin & 12.135 & 62.23 & 7.71 & 77.18 & 5.66 & 83.47 & 4.16 & $8^{\prime}$ \\
\hline 16 & Allethrin-1,2 & 12.909 & ND & - & - & - & 77.20 & 8.41 & $7 !$ \\
\hline 17 & $\begin{array}{l}\text { Allethrin-3,4 } \\
\text { (Bioallethrin) }\end{array}$ & 12.878 & ND & - & - & - & 139.75 & 6.07 & 9 \\
\hline 18 & Allidochlor & 4.887 & 103.00 & 2.41 & 108.16 & 1.76 & 99.01 & 0.92 & $8^{\prime}$ \\
\hline 19 & alpha-HCH & 9.303 & 81.33 & 4.99 & 101.52 & 6.40 & 95.63 & 5.91 & 8 \\
\hline 20 & alpha-Endosulfan & 13.661 & 81.67 & 14.40 & 86.38 & 15.11 & 111.85 & 15.14 & 1. \\
\hline 21 & Anthraquinone & 12.174 & 95.84 & 19.51 & 103.80 & 9.40 & 93.45 & 7.62 & 8 \\
\hline 22 & Atrazine & 9.755 & 108.77 & 2.56 & 111.74 & 4.29 & 102.18 & 2.25 & $8 i$ \\
\hline 23 & Azinphos-ethyl & 18.116 & 112.80 & 7.64 & 122.76 & 3.58 & 80.65 & 4.45 & 7 \\
\hline 24 & Azinphos-methyl & 16.747 & 72.83 & 15.57 & 120.94 & 7.43 & 119.47 & 6.39 & 9. \\
\hline 25 & Bendiocarb & 8.866 & 111.45 & 10.50 & 133.17 & 5.35 & 134.79 & 0.94 & 9. \\
\hline 26 & Benfluralin & 8.825 & 71.50 & 15.40 & 102.23 & 9.76 & 89.73 & 3.88 & 71 \\
\hline 27 & beta-HCH & 9.918 & 76.41 & 3.69 & 103.20 & 4.14 & 101.00 & 2.46 & 71 \\
\hline 28 & beta-Endosulfan & 14.852 & 85.93 & 17.28 & 71.17 & 19.10 & 116.32 & 13.23 & 11 \\
\hline 29 & Biphenyl & 5.946 & 81.91 & 3.10 & 90.14 & 3.12 & 89.48 & 3.90 & \\
\hline 30 & Bromfenvinfos-methyl & 12.869 & 86.04 & 13.83 & 132.81 & 9.77 & 85.40 & 9.64 & \\
\hline 31 & Bromfenvinphos & 13.647 & 76.90 & 9.39 & 99.78 & 13.11 & 95.30 & 15.61 & \\
\hline 32 & Bromophos & 12.457 & 76.09 & 7.61 & 95.61 & 8.50 & 82.41 & 2.48 & \\
\hline 33 & Bromophos-ethyl & 13.254 & 73.55 & 13.81 & 105.96 & 6.04 & ND & - & \\
\hline 34 & Bromopropylate & 16.833 & 78.48 & 9.79 & 96.55 & 1.47 & 72.28 & 8.03 & \\
\hline 35 & Bupirimate & 14.165 & 91.87 & 3.26 & 93.55 & 6.23 & 83.45 & 5.11 & \\
\hline 36 & Carbophenothion & 15.576 & 72.62 & 13.54 & 75.99 & 6.77 & 75.99 & 13.19 & \\
\hline 37 & Carfentrazone-ethyl & 15.454 & 91.87 & 12.10 & 93.59 & 3.01 & 94.95 & 10.26 & \\
\hline
\end{tabular}




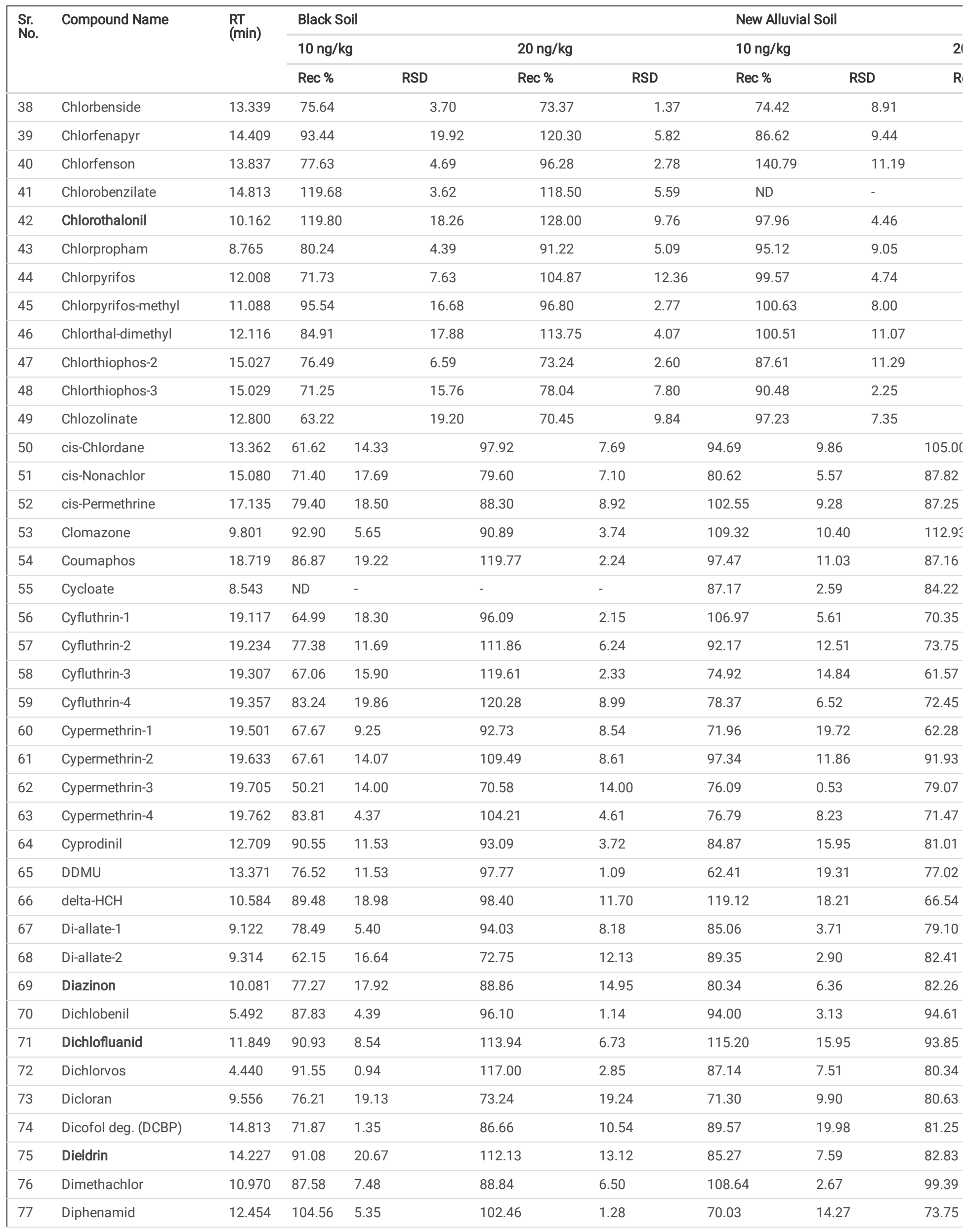




\begin{tabular}{|c|c|c|c|c|c|c|c|c|c|}
\hline \multirow{3}{*}{$\begin{array}{l}\text { Sr. } \\
\text { No. }\end{array}$} & \multirow[t]{3}{*}{ Compound Name } & \multirow{3}{*}{$\begin{array}{l}\text { RT } \\
\text { (min) }\end{array}$} & \multicolumn{4}{|c|}{ Black Soil } & \multicolumn{3}{|c|}{ New Alluvial Soil } \\
\hline & & & \multicolumn{2}{|c|}{10 ng/kg } & \multicolumn{2}{|c|}{$20 \mathrm{ng} / \mathrm{kg}$} & \multicolumn{2}{|c|}{$10 \mathrm{ng} / \mathrm{kg}$} & \multirow{2}{*}{$\frac{2}{\mathrm{R}}$} \\
\hline & & & $\operatorname{Rec} \%$ & RSD & $\operatorname{Rec} \%$ & RSD & $\operatorname{Rec} \%$ & RSD & \\
\hline 78 & Diphenylamine & 8.479 & 95.40 & 3.78 & 77.21 & 3.64 & 85.36 & 6.88 & 85.84 \\
\hline 79 & Disulfoton & 9.980 & 79.98 & 17.96 & 72.02 & 18.82 & 144.46 & 10.71 & 112.4 \\
\hline 80 & Edifenphos & 15.639 & 87.01 & 18.85 & 123.60 & 0.34 & 87.57 & 10.70 & 83.86 \\
\hline 81 & Endosulfan ether & 10.883 & 90.63 & 16.47 & 106.17 & 20.54 & 100.28 & 15.70 & 94.55 \\
\hline 82 & Endosulfan sulfate & 15.782 & 75.60 & 15.53 & 78.41 & 14.25 & 110.72 & 8.81 & 104.9( \\
\hline 83 & Endrin & 14.710 & ND & - & - & - & 108.35 & 8.36 & 88.28 \\
\hline 84 & Endrin aldehyde & 15.045 & 113.42 & 14.75 & 71.48 & 43.64 & 90.83 & 2.62 & 81.24 \\
\hline 85 & EPN & 15.729 & 87.50 & 14.60 & 89.23 & 18.90 & 101.11 & 7.63 & 79.13 \\
\hline 86 & Ethalfluralin & 8.611 & 88.41 & 18.21 & 75.20 & 10.03 & 58.45 & 11.72 & 71.79 \\
\hline 87 & Ethion & 14.961 & 78.80 & 8.76 & 96.35 & 0.61 & 82.32 & 5.67 & 76.68 \\
\hline 88 & Etofenprox & 18.025 & 75.40 & 12.25 & 79.60 & 14.62 & 101.80 & 2.89 & 86.66 \\
\hline 89 & Etridiazole & 6.565 & 80.39 & 7.78 & 95.27 & 4.67 & 90.51 & 3.20 & 71.94 \\
\hline 90 & Etrimfos & 10.424 & 79.99 & 13.92 & 108.53 & 3.06 & 106.73 & 13.12 & 91.56 \\
\hline 91 & Fenamiphos & 13.683 & 119.49 & 13.16 & 104.55 & 18.26 & 79.71 & 0.34 & 78.64 \\
\hline 92 & Fenarimol & 18.024 & 74.19 & 10.81 & 98.15 & 4.82 & 86.22 & 5.76 & 82.72 \\
\hline 93 & Fenchlorphos & 11.430 & 85.60 & 8.08 & 113.25 & 2.50 & 99.87 & 1.24 & 115.1' \\
\hline 94 & Fenitrothion & 11.692 & 106.38 & 15.86 & 124.20 & 4.19 & 94.31 & 15.06 & 85.70 \\
\hline 95 & Fenpropathrin & 16.703 & 106.08 & 13.08 & 102.54 & 4.51 & 80.92 & 2.24 & 82.38 \\
\hline 96 & Fenson & 12.444 & 72.18 & 2.25 & 93.88 & 1.80 & 80.91 & 2.39 & 7 \\
\hline 97 & Fenthion & 12.083 & 84.42 & 11.33 & 89.16 & 5.19 & 80.96 & 14.83 & 8: \\
\hline 98 & Fenvalerate-1 & 20.724 & 67.64 & 9.63 & 101.56 & 9.22 & 77.48 & 9.13 & 81 \\
\hline 99 & $\begin{array}{l}\text { Fenvalerate-2 } \\
\text { (Esfenvalerate) }\end{array}$ & 21.046 & 61.29 & 8.52 & 82.64 & 6.42 & 90.78 & 13.98 & 61 \\
\hline 100 & Fipronil & 12.798 & 70.18 & 16.67 & 74.56 & 20.23 & 61.39 & 13.28 & $7:$ \\
\hline 101 & Fipronil sulfide & 12.579 & 71.80 & 5.79 & 113.02 & 4.18 & 97.17 & 15.42 & 7 \\
\hline 102 & Fluazifop-P-butyl & 14.547 & 71.18 & 19.88 & 77.66 & 9.47 & 81.28 & 4.62 & 8 \\
\hline 103 & Fluchloralin & 10.156 & 58.81 & 13.59 & 86.54 & 14.28 & 94.31 & 12.52 & 71 \\
\hline 104 & Flucythrinate-1 & 18.050 & ND & - & - & - & 83.32 & 15.42 & $7 i$ \\
\hline 105 & Fludioxonil & 13.910 & 90.43 & 0.80 & 101.93 & 2.62 & 98.17 & 8.96 & 91 \\
\hline 106 & Fluquinconazole & 18.742 & 79.00 & 3.86 & 98.81 & 1.02 & 95.59 & 10.64 & 7: \\
\hline 107 & Fluridone & 20.273 & 101.66 & 9.09 & 90.84 & 5.23 & 116.23 & 15.28 & 11 \\
\hline 108 & Flusilazole & 14.179 & 73.46 & 19.31 & 80.88 & 9.74 & 87.36 & 3.27 & 8: \\
\hline 109 & Flutolanil & 13.766 & 74.02 & 3.90 & 87.01 & 1.33 & 60.97 & 6.59 & 61 \\
\hline 110 & Flutriafol & 13.692 & 102.69 & 11.33 & 100.15 & 4.29 & 77.22 & 10.01 & $8 !$ \\
\hline 111 & Fonofos & 10.095 & 78.59 & 13.28 & 71.94 & 6.83 & 93.85 & 6.27 & 91 \\
\hline 112 & gamma-HCH (Lindane) & 9.985 & 100.87 & 3.37 & 110.51 & 2.43 & 76.20 & 17.35 & 81 \\
\hline 113 & Heptachlor & 10.883 & 75.53 & 17.57 & 91.66 & 11.62 & 88.70 & 5.67 & 9: \\
\hline 114 & Heptachlor-exo-epoxide & 12.901 & 60.37 & 9.10 & 105.07 & 9.62 & 83.32 & 18.22 & 7 \\
\hline 115 & Hexachlorobenzene & 9.386 & 110.25 & 7.74 & 107.64 & 17.54 & ND & - & - \\
\hline 116 & Hexazinone & 15.908 & 72.40 & 18.06 & 74.21 & 13.77 & 107.08 & 20.41 & 11 \\
\hline 117 & lodofenphos & 13.814 & 76.79 & 5.83 & 115.49 & 3.54 & 89.14 & 11.25 & $8^{\circ}$ \\
\hline
\end{tabular}




\begin{tabular}{|c|c|c|c|c|c|c|c|c|c|}
\hline \multirow{3}{*}{$\begin{array}{l}\text { Sr. } \\
\text { No. }\end{array}$} & \multirow[t]{3}{*}{ Compound Name } & \multirow{3}{*}{$\begin{array}{l}\text { RT } \\
\text { (min) }\end{array}$} & \multicolumn{4}{|c|}{ Black Soil } & \multicolumn{3}{|c|}{ New Alluvial Soil } \\
\hline & & & \multicolumn{2}{|c|}{$10 \mathrm{ng} / \mathrm{kg}$} & \multicolumn{2}{|c|}{$20 \mathrm{ng} / \mathrm{kg}$} & \multicolumn{2}{|c|}{$10 \mathrm{ng} / \mathrm{kg}$} & \multirow{2}{*}{$\frac{2}{\mathrm{R}}$} \\
\hline & & & $\operatorname{Rec} \%$ & RSD & $\operatorname{Rec} \%$ & RSD & $\operatorname{Rec} \%$ & RSD & \\
\hline 118 & Isazofos & 10.338 & 72.04 & 17.27 & 88.38 & 1.90 & 112.25 & 5.48 & 91 \\
\hline 119 & Isodrin & 12.710 & 73.52 & 14.29 & 103.17 & 6.27 & 123.40 & 16.66 & 1 . \\
\hline 120 & Isopropalin & 12.506 & 63.11 & 16.50 & 89.08 & 2.56 & 89.04 & 18.42 & $8 i$ \\
\hline 121 & lambda-Cyhalothrin & 17.725 & 85.90 & 19.16 & 98.61 & 4.92 & 92.43 & 1.40 & 8 \\
\hline 122 & Lenacil & 15.780 & 96.89 & 4.74 & 90.46 & 6.51 & 119.11 & 8.54 & 81 \\
\hline 123 & Leptophos & 16.564 & 71.07 & 18.69 & 78.26 & 12.58 & 73.94 & 11.29 & 79 \\
\hline 124 & Linuron & 11.861 & 48.53 & 12.98 & 71.30 & 17.46 & 103.96 & 3.16 & 81 \\
\hline 125 & Malathion & 11.833 & 95.48 & 6.84 & 112.04 & 5.30 & 81.55 & 8.28 & 61 \\
\hline 126 & Metalaxyl (Mefenoxam) & 11.348 & 111.29 & 13.01 & 105.93 & 8.87 & 88.92 & 8.20 & 91 \\
\hline 127 & Metazachlor & 12.716 & 109.87 & 6.93 & 110.69 & 7.69 & 110.13 & 9.10 & 9 \\
\hline 128 & Methacrifos & 6.987 & 92.46 & 2.75 & 95.19 & 2.30 & 102.70 & 9.33 & 9 \\
\hline 129 & Methoxychlor & 16.074 & 88.05 & 10.25 & 110.38 & 6.19 & 71.23 & 12.62 & 81 \\
\hline 130 & $\begin{array}{l}\text { Metolachlor (S- } \\
\text { Metolachlor) }\end{array}$ & 11.975 & 102.04 & 12.99 & 110.44 & 2.08 & 125.28 & 19.75 & 11 \\
\hline 131 & Mevinphos-1 & 6.226 & 99.72 & 2.81 & 105.00 & 1.80 & 112.18 & 10.48 & 91 \\
\hline 132 & Mevinphos-2 & 6.226 & 99.72 & 2.81 & 105.00 & 1.80 & 112.18 & 10.48 & 91 \\
\hline 133 & MGK 264-1 & 12.466 & 82.49 & 19.63 & 91.64 & 13.64 & 98.91 & 5.64 & 9: \\
\hline 134 & MGK 264-2 & 12.712 & 86.39 & 12.48 & 71.38 & 7.97 & 90.43 & 4.90 & 91 \\
\hline 135 & Mirex & 17.921 & 78.83 & 7.81 & 92.77 & 1.85 & 76.36 & 13.09 & $7 !$ \\
\hline 136 & Myclobutanil & 14.167 & 91.65 & 7.96 & 95.07 & 3.92 & ND & - & - \\
\hline 137 & $\begin{array}{l}\mathrm{N}-(2,4 \text {-dimethylphenyl) } \\
\text { formamide }\end{array}$ & 6.923 & 104.42 & 4.02 & 98.36 & 1.42 & 111.87 & 3.19 & 91 \\
\hline 138 & Nitralin & 16.136 & 71.10 & 16.57 & 80.64 & 8.18 & 80.11 & 6.36 & 61 \\
\hline 139 & Nitrofen & 14.643 & 65.46 & 8.53 & 92.20 & 2.27 & ND & - & - \\
\hline 140 & Norflurazon & 15.620 & 86.92 & 9.27 & 83.26 & 7.48 & 76.14 & 5.73 & 8 \\
\hline 141 & o,p'-DDD & 14.247 & 71.39 & 1.26 & 93.66 & 2.86 & 114.92 & 5.35 & $9 i$ \\
\hline 142 & o,p'-DDE & 13.374 & 61.72 & 4.19 & 94.15 & 3.62 & 93.40 & 6.24 & 8 \\
\hline 143 & o,p'-DDT & 15.052 & 63.04 & 3.11 & 98.94 & 2.11 & 90.83 & 2.62 & 8 \\
\hline 144 & Oxadiazon & 14.013 & 79.07 & 18.34 & 87.81 & 4.41 & 102.37 & 5.63 & 8 \\
\hline 145 & Oxyfluorfen & 14.151 & 71.38 & 12.24 & 99.36 & 6.78 & 115.48 & 12.56 & 91 \\
\hline 146 & $p, p^{\prime}-D D D$ & 15.052 & 63.18 & 3.49 & 98.94 & 2.11 & 133.27 & 9.26 & 11 \\
\hline 147 & $\mathrm{p}, \mathrm{p}^{\prime}-\mathrm{DDE}$ & 14.071 & 61.53 & 8.08 & 97.30 & 2.92 & 85.72 & 8.57 & 81 \\
\hline 148 & p,p'-DDT & 15.829 & 67.20 & 3.94 & 82.91 & 3.61 & 101.46 & 14.44 & 8 \\
\hline 149 & Paclobutrazol & 13.468 & 90.02 & 16.53 & 92.76 & 1.32 & 82.55 & 5.58 & 8: \\
\hline 150 & paraoxon methyl & 10.305 & ND & - & - & - & 116.90 & 8.22 & $8^{\prime}$ \\
\hline 151 & Parathion & 12.161 & 97.29 & 14.65 & 103.02 & 11.19 & 139.85 & 5.66 & 81 \\
\hline 152 & Parathion-methyl & 11.206 & 89.93 & 14.37 & 110.98 & 1.99 & 70.20 & 7.12 & 8 \\
\hline 153 & Pebulate & 6.629 & 86.95 & 7.30 & 85.16 & 4.81 & 88.11 & 5.17 & 81 \\
\hline 154 & Penconazole & 12.802 & 83.52 & 8.65 & 92.27 & 5.70 & 100.62 & 11.04 & 9: \\
\hline 155 & Pendimethalin & 12.659 & 84.48 & 9.92 & 83.55 & 9.37 & 62.29 & 16.18 & 7: \\
\hline 156 & Pentachloroaniline & 10.883 & 90.78 & 12.15 & 75.53 & 19.56 & 92.00 & 17.32 & $8 !$ \\
\hline 157 & Pentachloroanisole & 9.483 & 84.24 & 8.74 & 105.31 & 5.44 & 74.59 & 7.66 & 8: \\
\hline
\end{tabular}




\begin{tabular}{|c|c|c|c|c|c|c|c|c|c|}
\hline \multirow{3}{*}{$\begin{array}{l}\text { Sr. } \\
\text { No. }\end{array}$} & \multirow[t]{3}{*}{ Compound Name } & \multirow{3}{*}{$\begin{array}{l}\text { RT } \\
\text { (min) }\end{array}$} & \multicolumn{4}{|c|}{ Black Soil } & \multicolumn{3}{|c|}{ New Alluvial Soil } \\
\hline & & & \multicolumn{2}{|c|}{$10 \mathrm{ng} / \mathrm{kg}$} & \multicolumn{2}{|c|}{$20 \mathrm{ng} / \mathrm{kg}$} & \multicolumn{2}{|c|}{$10 \mathrm{ng} / \mathrm{kg}$} & \multirow{2}{*}{$\frac{2}{\mathrm{R}}$} \\
\hline & & & $\operatorname{Rec} \%$ & RSD & $\operatorname{Rec} \%$ & RSD & $\operatorname{Rec} \%$ & RSD & \\
\hline 158 & Pentachlorobenzene & 7.377 & 79.69 & 9.28 & 104.46 & 2.31 & 93.41 & 4.11 & 8 \\
\hline 159 & Pentachlorobenzonitrile & 9.964 & 90.94 & 16.12 & 105.10 & 4.97 & 90.26 & 4.92 & 91 \\
\hline 160 & Pentachlorothioanisole & 11.857 & 75.04 & 17.62 & 95.74 & 15.19 & 100.34 & 7.92 & 8 \\
\hline 161 & Phenothrin-1 & 16.864 & ND & - & - & - & 109.10 & 4.87 & 81 \\
\hline 162 & Phorate & 9.139 & 78.30 & 18.09 & 71.22 & 20.03 & 97.29 & 10.31 & 9: \\
\hline 163 & phorate sulfide & 11.900 & 119.80 & 17.31 & 127.23 & 4.14 & 100.60 & 11.84 & 9: \\
\hline 164 & phorate sulfone & 12.024 & 100.34 & 2.91 & 121.59 & 5.56 & 92.65 & 12.40 & $9 i$ \\
\hline 165 & Piperonyl butoxide & 16.203 & 89.66 & 8.82 & 105.47 & 3.32 & 92.74 & 4.97 & 9. \\
\hline 166 & Pirimiphos ethyl & 12.383 & 80.51 & 11.64 & 82.59 & 5.60 & 84.18 & 9.48 & 8 \\
\hline 167 & Pirimiphos-methyl & 11.608 & 102.10 & 7.07 & 90.89 & 2.38 & 96.28 & 12.07 & 8 \\
\hline 168 & Pretilachlor & 13.875 & 85.10 & 12.99 & 98.86 & 3.91 & 107.23 & 14.09 & 11 \\
\hline 169 & Prochloraz & 18.797 & 80.53 & 6.39 & 98.73 & 7.24 & 58.67 & 13.09 & 71 \\
\hline 170 & Procymidone & 13.072 & 70.79 & 10.81 & 84.19 & 2.76 & 87.12 & 3.02 & $8^{\prime}$ \\
\hline 171 & Prodiamine & 11.670 & 61.53 & 18.04 & 115.91 & 12.32 & 90.89 & 9.38 & 8 \\
\hline 172 & Profenofos & 13.968 & 105.80 & 15.65 & 130.61 & 8.16 & 80.14 & 10.41 & 8: \\
\hline 173 & Profluralin & 9.880 & 64.49 & 13.97 & 103.64 & 3.63 & 94.48 & 2.00 & 7. \\
\hline 174 & Propachlor & 8.233 & 98.15 & 1.67 & 97.40 & 4.15 & 117.68 & 6.13 & 91 \\
\hline 175 & Propanil & 11.084 & 76.15 & 9.60 & 88.66 & 17.70 & ND & - & - \\
\hline 176 & Propargite-1 & 16.120 & 113.10 & 16.90 & 127.80 & 6.55 & 96.86 & 7.31 & 7 \\
\hline 177 & Propargite-2 & 16.120 & 98.23 & 19.70 & 125.40 & 7.31 & 93.39 & 13.21 & $8:$ \\
\hline 178 & Propisochlor & 11.306 & 77.55 & 8.92 & 91.01 & 8.77 & 88.38 & 4.07 & 8 \\
\hline 179 & Propoxur & 8.210 & 97.81 & 12.18 & 131.19 & 3.32 & 88.28 & 2.03 & 91 \\
\hline 180 & Propyzamide & 10.116 & 96.88 & 7.67 & 107.32 & 3.99 & 87.04 & 8.35 & 81 \\
\hline 181 & Prothiofos & 13.865 & 75.30 & 7.78 & 91.67 & 6.23 & 98.46 & 11.62 & 11 \\
\hline 182 & Pyraclofos & 18.236 & 71.34 & 12.45 & 102.91 & 9.78 & 85.95 & 14.17 & 9. \\
\hline 183 & Pyrazophos & 17.936 & 97.08 & 8.81 & 104.40 & 3.17 & 83.93 & 14.46 & $7 !$ \\
\hline 184 & Pyridaben & 18.747 & 76.41 & 6.81 & 90.59 & 2.49 & 62.75 & 5.04 & $6^{\circ}$ \\
\hline 185 & Pyridaphenthion & 16.567 & 107.13 & 5.88 & 98.21 & 2.95 & 87.70 & 8.89 & 81 \\
\hline 186 & Pyrimethanil & 10.247 & 85.19 & 5.52 & 79.41 & 6.16 & 89.65 & 16.53 & 9. \\
\hline 187 & Pyriproxyfen & 17.584 & 85.12 & 9.86 & 104.03 & 4.95 & 99.98 & 15.38 & 81 \\
\hline 188 & Quinalphos & 12.982 & 98.22 & 7.49 & 111.18 & 6.57 & 131.31 & 19.70 & 1. \\
\hline 189 & Quintozene & 9.874 & 120.00 & 13.11 & 104.72 & 6.29 & 140.22 & 12.15 & 6 \\
\hline 190 & Resmethrin-1 & 15.967 & 71.69 & 18.60 & 74.62 & 3.98 & 101.10 & 16.96 & 9: \\
\hline 191 & $\begin{array}{l}\text { Resmethrin-2 } \\
\text { (Bioresmethrin) }\end{array}$ & 15.997 & 83.63 & 10.29 & 75.83 & 1.41 & 78.83 & 2.65 & 8: \\
\hline 192 & Sulfotep & 8.861 & 78.55 & 16.81 & 90.27 & 7.15 & 82.63 & 3.26 & 7 \\
\hline 193 & Sulprofos & 15.336 & 78.99 & 18.90 & 75.00 & 15.88 & 78.74 & 17.31 & 81 \\
\hline 194 & tau-Fluvalinate-1 & 20.883 & 70.86 & 8.75 & 127.54 & 3.49 & 96.89 & 10.63 & 71 \\
\hline 195 & tau-Fluvalinate-2 & 20.992 & 74.57 & 16.46 & 117.31 & 4.23 & 84.21 & 6.42 & 7: \\
\hline 196 & Tebuconazole & 16.124 & 83.86 & 3.88 & 88.13 & 7.11 & 97.79 & 8.43 & $9^{\circ}$ \\
\hline 197 & Tebufenpyrad & 17.038 & 86.62 & 12.38 & 94.95 & 3.44 & 119.85 & 13.26 & 1 . \\
\hline
\end{tabular}




\begin{tabular}{|c|c|c|c|c|c|c|c|c|c|}
\hline \multirow{3}{*}{$\begin{array}{l}\text { Sr. } \\
\text { No. }\end{array}$} & \multirow[t]{3}{*}{ Compound Name } & \multirow{3}{*}{$\begin{array}{l}\text { RT } \\
\text { (min) }\end{array}$} & \multicolumn{4}{|c|}{ Black Soil } & \multicolumn{3}{|c|}{ New Alluvial Soil } \\
\hline & & & \multicolumn{2}{|c|}{10 ng/kg } & \multicolumn{2}{|c|}{$20 \mathrm{ng} / \mathrm{kg}$} & \multicolumn{2}{|c|}{$10 \mathrm{ng} / \mathrm{kg}$} & \multirow{2}{*}{$\frac{2}{\mathrm{R}}$} \\
\hline & & & $\operatorname{Rec} \%$ & RSD & $\operatorname{Rec} \%$ & RSD & $\operatorname{Rec} \%$ & RSD & \\
\hline 198 & Tecnazene & 8.113 & 70.96 & 4.87 & 79.35 & 5.01 & 78.14 & 17.32 & 8 \\
\hline 199 & Tefluthrin & 10.332 & 72.88 & 10.08 & 95.77 & 0.18 & 96.37 & 8.86 & 9: \\
\hline 200 & Terbacil & 10.444 & 116.11 & 9.61 & 107.35 & 8.34 & 79.78 & 7.83 & $7 i$ \\
\hline 201 & Terbufos & 9.986 & 96.59 & 16.03 & 92.05 & 11.28 & 100.66 & 13.55 & 91 \\
\hline 202 & Terbuthylazine & 10.025 & 110.45 & 16.25 & 112.26 & 1.39 & 71.23 & 2.59 & 9 \\
\hline 203 & Tetrachlorvinphos & 13.373 & 94.32 & 12.52 & 91.83 & 11.50 & 87.77 & 4.36 & 71 \\
\hline 204 & Tetradifon & 16.432 & 71.96 & 18.22 & 71.43 & 22.45 & 90.82 & 4.39 & $7 i$ \\
\hline 205 & Tetramethrin-1 & 15.933 & ND & - & - & - & 110.05 & 2.79 & $5 i$ \\
\hline 206 & $\begin{array}{l}\text { THPI } \\
\text { (Tetrahydrophthalimide) }\end{array}$ & 7.055 & 86.76 & 7.63 & 95.85 & 7.89 & 93.32 & 2.98 & $8^{\prime}$ \\
\hline 207 & Tolclofos-methyl & 11.236 & 99.86 & 15.87 & 111.16 & 9.18 & 102.99 & 3.01 & 91 \\
\hline 208 & Tolylfluanid & 12.832 & 87.90 & 12.22 & 120.84 & 1.92 & 81.07 & 12.27 & 9 \\
\hline 209 & trans-Chlordane & 13.621 & 70.53 & 13.39 & 94.33 & 3.27 & 117.22 & 21.41 & $8^{\prime}$ \\
\hline 210 & Transfluthrin & 11.233 & 52.58 & 14.57 & 92.06 & 3.79 & 82.81 & 6.40 & 8: \\
\hline 211 & trans-Nonachlor & 13.705 & 49.90 & 22.12 & 70.75 & 18.89 & 80.62 & 5.48 & 8 \\
\hline 212 & trans-Permethrine & 17.306 & 49.78 & 12.07 & 88.13 & 6.49 & 89.39 & 5.79 & 8 \\
\hline 213 & Triadimefon & 12.196 & 109.15 & 12.47 & 105.20 & 10.58 & 75.23 & 11.79 & 71 \\
\hline 214 & Triadimenol-1 & 13.083 & 94.38 & 11.49 & 95.97 & 3.99 & 119.39 & 13.31 & 1 \\
\hline 215 & Tri-allate & 10.489 & 79.96 & 7.17 & 96.47 & 5.11 & 73.92 & 12.91 & $8:$ \\
\hline 216 & Triazophos & 15.305 & 77.38 & 12.55 & 100.06 & 7.59 & 83.06 & 12.49 & 91 \\
\hline 217 & Tricyclazole & 14.060 & 70.16 & 16.12 & 92.80 & 2.66 & 118.21 & 3.65 & 8 \\
\hline 218 & Triflumizole & 13.077 & 90.91 & 17.85 & 103.09 & 13.81 & 81.50 & 13.27 & 7 \\
\hline 219 & Trifluralin & 8.769 & 70.99 & 7.86 & 99.04 & 3.75 & 92.50 & 5.60 & 8 \\
\hline 220 & Vinclozolin & 11.172 & 70.19 & 8.67 & 89.82 & 3.28 & 74.79 & 15.65 & 8 \\
\hline
\end{tabular}

\section{Figures}




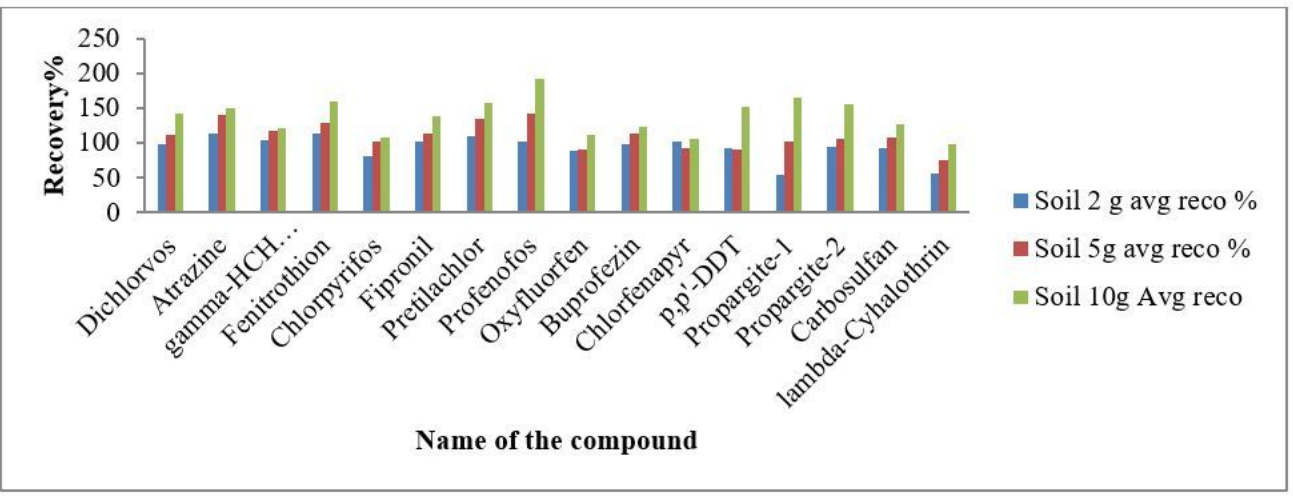

Fig. 1a

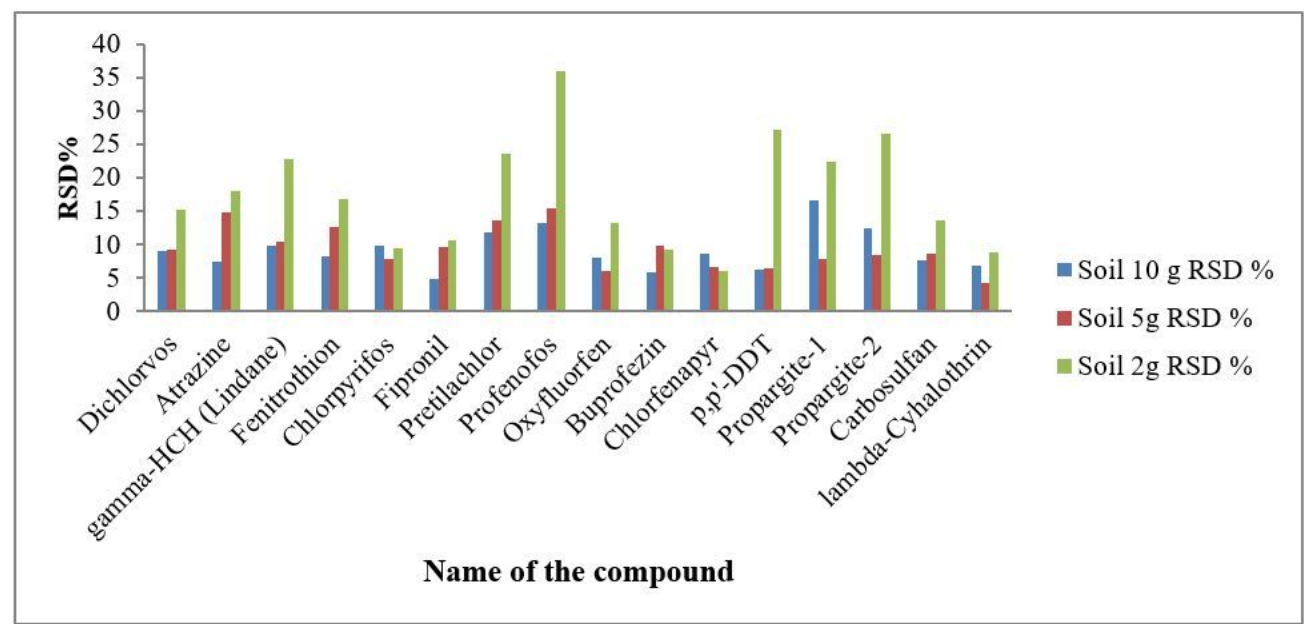

Fig. 1b

\section{Figure 1}
1a. Sample size optimisation in BS (pesticides with recovery \%)
1b. Sample size optimisation in BS (pesticides with RSD \%) 


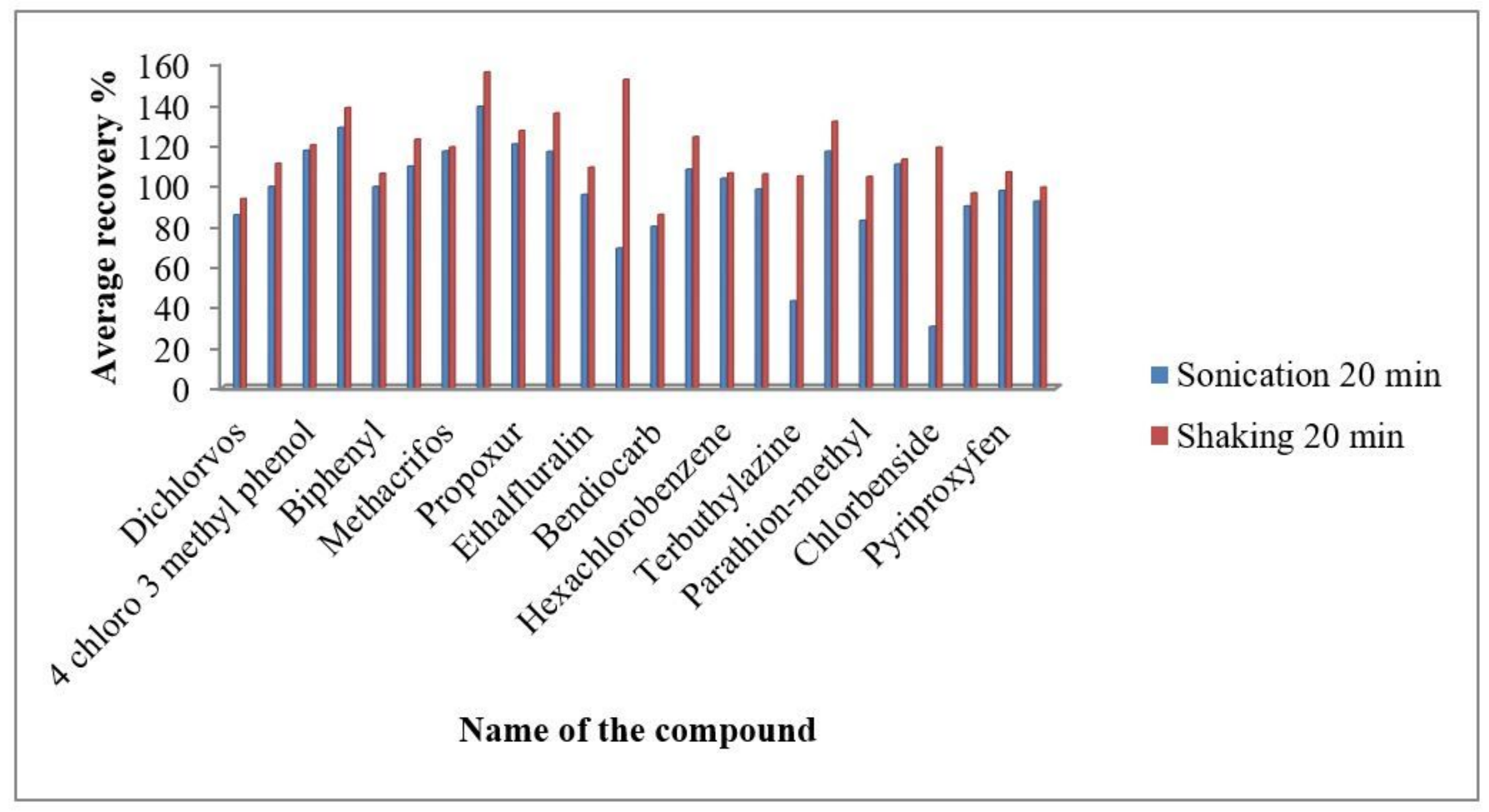

Figure 2

Shaking versus sonication (pesticides with average recovery \%) 


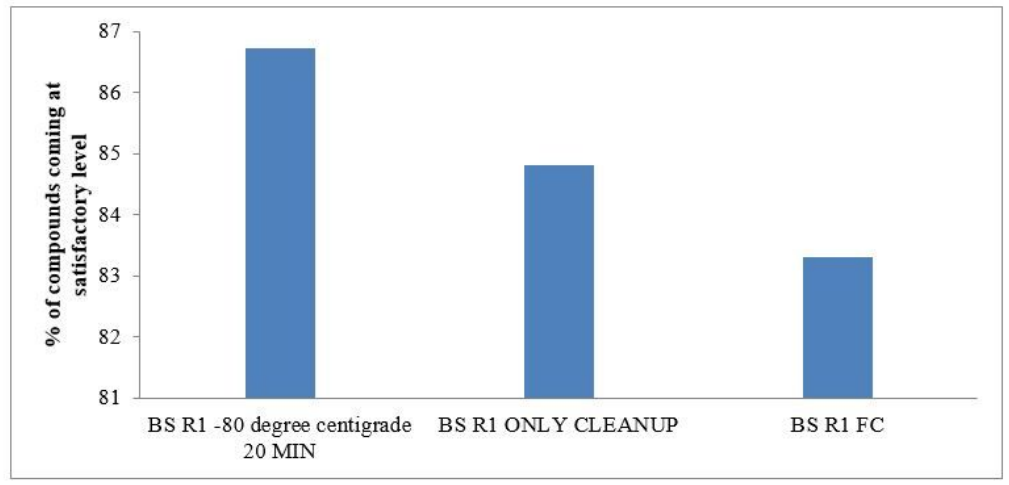

Fig. 3a

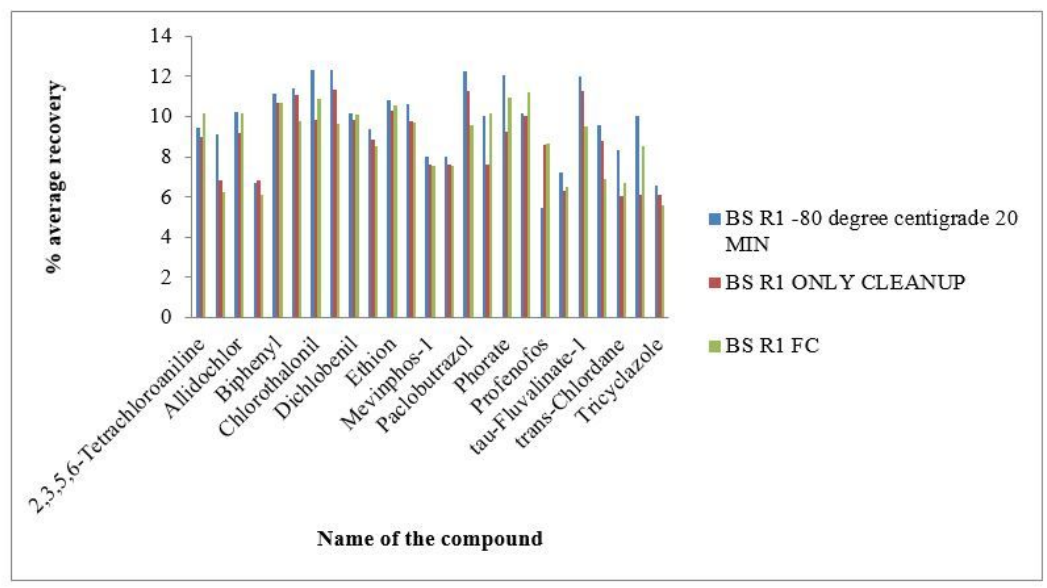

Fig. 3b

\section{Figure 3}

3a. Per cent of compounds recovered with satisfactory accuracy for different cleanup procedures 3b. Average recovery (\%) data of selected pesticides in BS for different cleanup procedures 


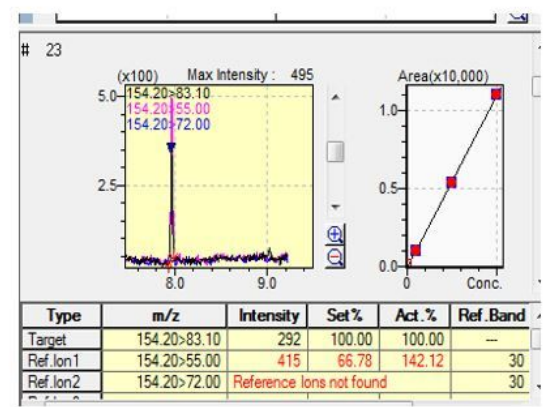

Fig. 4a.

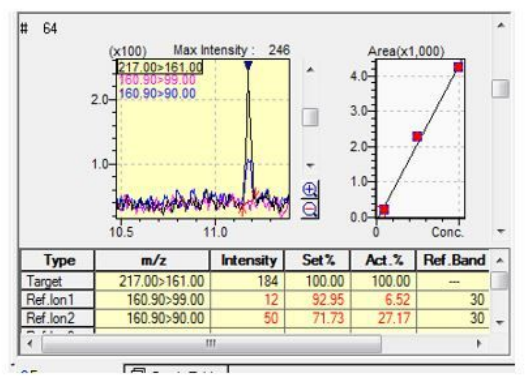

Fig. 4b

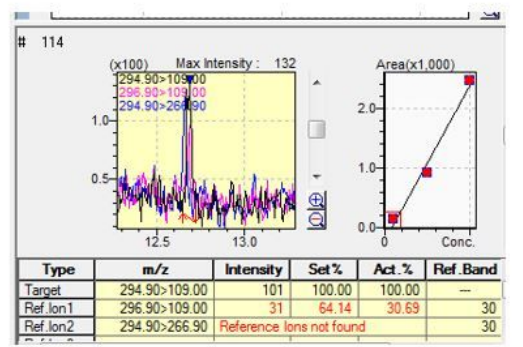

Fig. 4c

\section{Figure 4}

4a. False detection of cycloate in BS

4b. False detection of propanil in NAS

4c. False detection of bromofenvinphos in RS

\section{Supplementary Files}

This is a list of supplementary files associated with this preprint. Click to download.

- SupplementaryFigures.docx

- SupplementaryTables.docx 